\title{
Internal ribosome entry sites in eukaryotic mRNA molecules
}

\author{
Christopher U.T. Hellen ${ }^{1,3}$ and Peter Sarnow ${ }^{2,3}$ \\ ${ }^{1}$ Department of Microbiology and Immunology, Morse Institute for Molecular Genetics, State University of New York \\ Health Science Center at Brooklyn, Brooklyn, New York 11203, USA; ${ }^{2}$ Department of Microbiology and Immunology, \\ Stanford University School of Medicine, Stanford, California 94305, USA
}

Initiation of translation of most eukaryotic mRNAs commences with 5' end-dependent recruitment of 40S ribosomal subunits to the mRNA. The $40 \mathrm{~S}$ subunit carrying the initiator methionine-tRNA and certain eukaryotic initiation factors (eIFs) is thought to scan the mRNA in a $5^{\prime}$ to $3^{\prime}$ direction until an appropriate start codon is encountered at which stage a 605 subunit joins to form an $80 \mathrm{~S}$ ribosome that can decode the RNA into protein (Kozak 1989; Hershey and Merrick 2000). A subset of mRNAs contains internal ribosomal entry sites (IRESs), usually in the $5^{\prime}$ NTR, that enable end-independent initiation to occur. IRES-containing mRNAs are not subjected to many of the regulatory mechanisms that control recruitment of most mRNAs to the translation apparatus. In this review, we briefly provide an introduction to the known mechanisms of translation initiation. Then, we discuss in detail the molecular mechanisms of IRES-mediated initiation and how they are used by specific mRNAs to permit translation under physiological circumstances such as mitosis, apoptosis, hypoxia, and some viral infections when translation of most mRNAs is repressed.

\section{Mechanisms that mediate translation initiation}

Most vertebrate mRNAs are functionally monocistronic and contain a $5^{\prime}$-terminal $\mathrm{m}^{7} \mathrm{GpppN}$ (where $\mathrm{N}$ can be any nucleotide) cap structure. The initiation codon used as the start site for protein synthesis is preceded by a $5^{\prime}$ nontranslated region (NTR) in which length, nucleotide composition, and structure can determine the efficiency and the mechanism by which a given mRNA is translated (Hershey and Merrick 2000). For the most part, the factors that influence the binding of $40 \mathrm{~S}$ subunits to the mRNA provide the limiting step in translation initiation. In recent years, it has been found that a particular initiation mechanism can be used preferentially when

${ }^{3}$ Corresponding authors.

E-MAIL chellen@netmail.hscbklyn.edu; FAX (718) 270-2656.

E-MAIL psarnow@leland.stanford.edu; FAX (650) 498-7147.

Article and publication are at http://www.genesdev.org/cgi/doi/10.1101/ gad.891101. one or more specific initiation factors are limiting. Thus, it is crucial to the understanding of translational regulation to know the requirements of each initiation mechanism for translation factors.

\section{The canonical scanning mechanism of translation initiation}

Genetic and biochemical evidence has shown that most mRNAs in eukaryotic cells recruit ribosomes by a mechanism in which a $43 \mathrm{~S}$ complex, composed of a $40 \mathrm{~S}$ subunit bound to eIF2-GTP/Met-tRNA i $_{\text {, }}$ eIF1A, and eIF3 (Table 1), is recruited at the capped 5' end (Kozak 1989; Donahue 2000; Hershey and Merrick 2000). Binding of the 43S complex to mRNA involves recognition of the 5' capped mRNA by the eIF4E (cap-binding) subunit of eIF4F (Table 1) and is greatly enhanced by the poly(A)binding protein (PABP) bound to the $3^{\prime}$ poly(A) tail (for review, see Sachs and Varani 2000). The cap-binding protein complex eIF4F comprises eIF4E, eIF4A, and eIF4G subunits (Table 1). eIF4A is a DEAD-box RNA helicase/ RNA-dependent ATPase that exists both free and as part of eIF4F. The helicase activities of eIF4A and eIF4F are strongly enhanced by eIF4B. eIF4G is a large polypeptide and acts as a molecular scaffold that binds eIF3, eIF4A, eIF4E, and PABP and coordinates their activities (Hentze 1997; Gingras et al. 1999).

The mechanism that recruits $43 \mathrm{~S}$ complexes onto the mRNA is not known. One hypothesis is that the attachment of the $43 \mathrm{~S}$ complex is mediated by interactions between the eIF4G subunit of cap-bound eIF4F and the eIF3 component of the 43S complex, as well as between the mRNA and eIF4G, eIF3 and the 40S subunit (Lamphear et al. 1995). After attachment, eIF1 and eIF1A act synergistically to enable scanning of the $43 \mathrm{~S}$ complex in a $5^{\prime}$ to $3^{\prime}$ direction from its initial binding site to the initiation codon (Pestova et al. 1998a). In support of this model, genetic analyses in yeast have implicated eIF1, eIF2, and eIF5 in initiation codon recognition (Donahue 2000). The resulting ribosomal 48 S complex in which base pairing between the initiation codon of mRNA and the anticodon of initiator tRNA has been established 
Table 1. Characteristics of mammalian translation initiation factors

\begin{tabular}{lccl}
\hline Name & Subunits & Mass $(\mathrm{kD})$ & \multicolumn{1}{c}{ Function } \\
\hline elF1 & 1 & 12.6 & Enables ribosomes to scan; destabilizes aberrant initiation complexes \\
elF1A & 1 & 16.5 & Promotes binding of Met-tRNA to 40S subunit; promotes ribosomal scanning \\
elF2 & 3 & 126 & GTP-dependent binding of Met-tRNA to 40S subunit; GTPase \\
elF2B & 5 & 261 & Guanine nucleotide exchange factor for elF2 \\
elF3 & 11 & $\sim 700$ & Ribosomal dissociation; promotes binding of mRNA and Met-tRNA to 40S subunit \\
elF4A & 1 & 44 & RNA-dependent ATPase; RNA helicase \\
elF4B & 1 & 70 & Promotes RNA helicase activity of elF4A, elF4F \\
elF4E & 1 & 26 & m $^{7}$ G cap-binding subunit \\
elF4G & 1 & 154 & Binds RNA, PABP, elF4E, elF4A, elF3 \\
elF4F & 3 & 223 & elF4E/4A/4G heterotrimer: binds ${ }^{7}$ G caps, RNA helicase \\
elF5 & 1 & 49 & Activates GTPase activity of elF2 \\
elF5B & 1 & 139 & Ribosomal subunit joining; GTPase \\
\hline
\end{tabular}

contains eIF1, eIF1A, eIF3, and eIF2-GTP/Met-tRNA . eIF5 induces hydrolysis of eIF2-bound GTP, leading to displacement of eIF2-GDP; the inactive eIF2-GDP is recycled to the active eIF2-GTP by eIF2B, a guanine nucleotide exchange factor (Table 1; Hershey and Merrick 2000). Finally, eIF5B (Table 1) mediates joining of a $60 S$ subunit to the $40 S$ subunit, resulting in formation of an 80S ribosome in which initiator tRNA is positioned in the ribosomal $\mathrm{P}$ site and that is competent to begin protein synthesis (Pestova et al. 2000).

The scanning mechanism predicts that mRNAs are most efficiently translated if their $5^{\prime}$ NTRs are relatively unstructured and at times when none of the eIFs is limiting. As discussed below, these requirements become simplified for other initiation mechanisms.

\section{Leaky scanning and reinitiation}

Initiation usually occurs at the AUG triplet that is proximal to the $5^{\prime}$ end of an mRNA. Although the most efficiently used AUG triplets are embedded within the sequence ACCAUGG (the initiation codon is underlined; Kozak 1987), almost any AUG can be used. If pyrimidine residues occupy positions -3 or +4 (if the adenosine in the AUG triplet is designated as +1 ), the scanning ribosomal complex may bypass the embedded AUG by leaky scanning (Kozak 1989).

It is possible for ribosomes to reinitiate after translation of an upstream open reading frame (Morris and Geballe 2000). In the best characterized example, reinitiation on GCN4 mRNA in Saccharomyces cerevisiae is regulated by amino acid availability that determines the level of ternary eIF2/GTP/initiator tRNA complexes and thus the rate at which ribosomes become competent to reinitiate after termination (Hinnebusch 1997).

A low proportion of eukaryotic mRNAs, mostly encoding regulatory proteins, have very long, highly structured 5' NTRs that contain multiple AUG triplets (Kozak 1991). Deletion of such highly structured or AUG-burdened 5' NTRs from mRNAs improves expression of the encoded protein (e.g., Marth et al. 1988; Arrick et al. 1991). However, certain viral and cellular mRNAs that contain long structured 5' NTRs can be translated very efficiently at times when other leaderburdened mRNAs are not. Two mechanisms, both operationally distinct from the canonical scanning mechanism, have been discovered that can account for the translation of such mRNAs: ribosomal shunting and internal initiation.

\section{Ribosomal shunting}

Ribosomal shunting has been found to mediate translation initiation on a few viral mRNAs, including cauliflower mosaic virus 35S mRNA (Futterer et al. 1993) and adenovirus late mRNAs (Yueh and Schneider 1996) and on the cellular mRNA that encodes heat shock protein 70 (Yueh and Schneider 2000). In this mechanism, ribosomal subunits bind the mRNA in a 5' cap-dependent manner and scan downstream until a stable RNA structure is encountered that may arrest the scanning ribosomes or cause them to dissociate from the RNA. This arrest is followed by intramolecular shunting of the ribosomal subunit to a downstream landing site, bypassing the RNA structure. The ribosome resumes scanning until the next appropriate start codon is encountered. Although the mechanism of ribosomal shunting is not known, RNA sequences located between the hairpins and the initiation codon, some of which are complementary to sequences located near the $3^{\prime}$ end of $18 \mathrm{~S}$ ribosomal RNA, play an important role. It has been speculated that the $18 \mathrm{~S}$-complementary sequences interact directly with the $40 \mathrm{~S}$ subunit to provide a landing site after it has bypassed the hairpins (Yueh and Schneider 2000). Whether shunting is commonly used as a means of efficiently translating mRNAs burdened with secondary structures in their $5^{\prime}$ NTRs is not known.

\section{Internal initiation}

Twenty-two years ago, it was reported that prokaryotic, but not eukaryotic, ribosomes could bind circular RNA molecules, suggesting that eukaryotic ribosomes enter mRNAs exclusively via their free 5' ends (Kozak 1979; Konarska et al. 1981). 
However, it was also known that RNA genomes of picornaviruses such as encephalomyocarditis virus (EMCV) and poliovirus have properties that are incompatible with initiation by 5 ' end-dependent scanning. In 1988, it was discovered that picornaviral mRNAs are translated by a mechanism, distinct from shunting, that enables ribosomes to initiate translation effectively on highly structured regions located within the 5' NTRs (Jang et al. 1988; Pelletier and Sonenberg 1988). These regions were named IRESs.

\section{Internal ribosome entry site}

\section{Discovery of IRES elements}

Picornaviral 5' NTRs can range in length from 610 to 1500 nucleotides, are highly structured, and contain multiple nonconserved AUG triplets upstream of the initiation codon that should act as strong barriers to scanning ribosomes. Although one could imagine that a sophisticated combination of leaky scanning and reinitiation guides a scanning $40 S$ subunit to the start site codon, several lines of experimentation over the past decade have argued that this is not the case.

First, changing six of the seven AUG codons in the polioviral 5' NTR to UUG, a scenario that should affect the rate of reinitiation, did not alter the efficiency of initiation (Pelletier et al. 1988). Second, polysome-associated picornaviral RNAs have a $5^{\prime} \mathrm{pUp}$ terminus, instead of the commonly found 5' cap structure (Nomoto et al. 1977). This finding suggested that translation of the viral mRNA does not need the eIF4E cap-binding subunit of eIF4F that normally recruits 40S subunits to capped 5' ends. Indeed, picornaviral mRNA translation is not inhibited when eIF4E is sequestered by cap analogs in vitro (e.g., Canaani et al. 1976), by increased concentrations of eIF4E-binding proteins (eIF4-BPs) in vitro and in vivo (Pause et al. 1994a), or by treatment of cultured cells with rapamycin to induce the dephosphorylation of eIF4BPs, which sequester eIF4E in eIF4E/eIF4-BP complexes (Beretta et al. 1996). Additional support that translation of all picornaviral mRNAs (except hepatitis A virus) was independent of an intact cap-binding protein complex (eIF4F) came from studies conducted to examine the mechanism by which picornaviruses rapidly inhibit translation of capped cellular mRNAs in infected cells. Some picornaviruses such as poliovirus and foot-andmouth disease virus (FMDV), encode proteases that cleave both isoforms of eIF4G separating eIF4G into $\mathrm{N}$ terminal eIF4G/eIF4E/PABP and C-terminal eIF4G/ eIF4A/eIF3 complexes, thereby uncoupling the cap recognition from ribosome-binding and helicase functions of eIF4F (Lamphear et al. 1993, 1995; Gradi et al. 1998). In addition, sequestration of eIF4E by eIF4-BPs is increased as a result of EMCV and poliovirus infection of cells (Gingras et al. 1996). Both mechanisms strongly reduce the activity of eIF4F in cap-mediated initiation on host cell mRNAs during viral infections.

All of the above results indicated that picornaviral mRNAs must be translated by a cap-independent initia- tion mechanism. This notion was verified when it was shown that the 5' NTRs of EMCV and poliovirus could mediate internal entry of ribosomes. Specifically, insertion of these viral 5' NTRs into the intercistronic spacer region of a dicistronic mRNA mediated translation of the second cistron (Jang et al. 1988; Pelletier and Sonenberg 1988). Translation of the downstream cistron occurred even when translation of the upstream cistron was abolished, but was dependent on the integrity of the inserted 450 -nt long IRES. Small deletions or insertions, and even substitution of single nucleotides in the IRES elements, severely reduced their activity (Svitkin et al. 1985; Kuge and Nomoto 1987; Trono et al. 1988).

Not surprisingly, the first IRES element in a cellular mRNA, encoding the immunoglobulin heavy chain binding protein $\mathrm{BiP}$, was discovered by its continuing activity in poliovirus infected cells at a time when the bulk of host cell mRNA translation was inhibited (Sarnow 1989; Macejak and Sarnow 1991). In more recent studies, additional IRES-containing cellular mRNAs have been identified in poliovirus-infected cells (Johannes and Sarnow 1998; Johannes et al. 1999). Note that certain mRNAs can be translated under such conditions that do not contain IRESs, such as the late adenoviral mRNAs that are translated by a shunting mechanism (Dolph et al. 1988).

So far, all picornaviral mRNAs have been found to contain IRES elements. Table 2 provides a list of RNA viruses and one DNA virus, Kaposi's sarcoma-associated herpesvirus, whose genomes contain IRES elements.

Table 2. Internal ribosome entry sites in viral genomes

\begin{tabular}{|c|c|}
\hline Virus & Reference \\
\hline Poliovirus & Pelletier and Sonenberg 1988 \\
\hline Rhinovirus & Borman and Jackson 1992 \\
\hline Encephalomyocarditis virus & Jang et al. 1988 \\
\hline $\begin{array}{l}\text { Foot-and-mouth disease } \\
\text { virus }\end{array}$ & Kuhn et al. 1990 \\
\hline Hepatitis $\mathrm{C}$ virus & Tsuklyama-Kohara et al. 1992 \\
\hline Classic Swine Fever Virus & Rijnbrand et al. 1997 \\
\hline Bovine viral diarrhea virus & Poole et al. 1995 \\
\hline $\begin{array}{l}\text { Friend murine leukemia } \\
\text { virus gag mRNA }\end{array}$ & Berlioz and Darlix 1995 \\
\hline $\begin{array}{l}\text { Moloney murine leukemia } \\
\text { virus gag mRNA }\end{array}$ & Vag1 \\
\hline Rous sarcoma virus & Deffaud and Darlix 2000 \\
\hline $\begin{array}{l}\text { Human immunodeficiency } \\
\text { virus env mRNA }\end{array}$ & Buck et al. 2001 \\
\hline Plautia stali intestine virus & Sasaki and Nakashima 1999 \\
\hline Rhopalosiphum padi virus & Domier et al. 2000 \\
\hline Cricket paralysis virus & Wilson et al. $2000 \mathrm{~b}$ \\
\hline $\begin{array}{l}\text { Kaposi's sarcoma-associated } \\
\text { herpesvirus }\end{array}$ & $\begin{array}{c}\text { Grundhoff and Ganem 2001; } \\
\text { Bieleski and Talbot } 2001\end{array}$ \\
\hline
\end{tabular}

Listed are IRES elements that passed at least two tests when located in the intergenic region in a dicistronic mRNA: IRES is intact after translation in a cell-free system or in cultured cells expressing the dicistronic gene. IRES-mediated translation of the second cistron is independent of the translation of the first cistron.

(IRES) internal ribosomal entry site. 
Table 3 lists cellular mRNAs that contain IRES activity. As will be discussed below, all viral IRES elements need to maintain a specific higher-ordered RNA structure to be functional. This feature contrasts with some cellular IRESs for which short, noncontiguous segments can mediate internal ribosome entry.

\section{Experimental test for IRES activity}

The recent flurry of newly discovered IRES elements in both viral and cellular mRNAs warrants a brief discussion about the experimental criteria that should be applied to an RNA sequence before it is termed an IRES. First, and most importantly, the integrity of the translated dicistronic mRNA, which contains a suspected IRES element in the intergenic region, has to be examined to evaluate other possible reasons for translation of the downstream cistron. Care must be taken if sensitive enzymatic assays are used to monitor translation of the second cistron because small amounts of broken dicistronic RNAs could yield functionally monocistronic RNA that, although uncapped, can be translated into active enzyme. In addition, it has to be determined whether intercistronic spacer regions can provide promoter activity or contain cryptic splice sites that could lead to synthesis of functionally monocistronic mRNA; the first of these scenarios is often encountered in $S$. cerevisiae in which TATA-like sequences can function as a promoter. Second, IRES-mediated translation of the second cistron must be independent of translation of the first cistron to rule out mechanisms such as termination-reinitiation as a cause of translation of the downstream cistron. A particular convincing demonstration of IRES-mediated initiation involves the insertion of a suspected IRES into a circularized RNA, engineered to contain a single continuous open reading frame, so that multiple rounds of translation of the circle can be used as a measure of its integrity (Chen and Sarnow 1995).

\section{Mechanism of ribosome recruitment by picornaviral IRES elements}

So far, the dicistronic mRNA translation assay has been used to identify IRES elements in viral genomes (Table 2) and in a broad range of cellular mRNAs from mammals to insects (Table 3). There are few, if any, convincing similarities between IRES elements in terms of sequence, size, or structure except for those from families of related viruses. The implication is that there is no universal mechanism of internal ribosomal entry, or that an elusive Shine-Dalgarno-like sequence, perhaps created by secondary or tertiary structure, cannot be easily detected in IRESs.

Much is known about the sequence and factors that recruit ribosomal subunits to picornavirus, hepatitis $\mathrm{C}$ virus, and cricket paralysis virus IRESs. Thus, we first discuss three fundamentally different mechanisms of initiation used by viral IRES elements.
Table 3. Internal ribosome entry sites in cellular mRNAs

\begin{tabular}{|c|c|}
\hline Gene product & Reference \\
\hline \multicolumn{2}{|l|}{ Growth factors } \\
\hline $\begin{array}{l}\text { Fibroblast growth factor } 2 \\
\text { (FGF2) }\end{array}$ & Vagner et al. 1995a \\
\hline $\begin{array}{l}\text { Platelet-derived growth } \\
\text { factor B (PDGF/c-sis) }\end{array}$ & Bernstein et al. 1997 \\
\hline $\begin{array}{l}\text { Vascular endothelial } \\
\text { growth factor (VEGF) }\end{array}$ & $\begin{array}{l}\text { Akiri et al. 1998; Stein et al. } \\
\text { 1998; Huez et al. } 1998\end{array}$ \\
\hline Cyr61 & Johannes et al. 1999 \\
\hline \multicolumn{2}{|l|}{ Transcription factors } \\
\hline Antennapedia & Oh et al. 1992; Ye et al. 1997 \\
\hline Ultrabithorax & Ye et al. 1997 \\
\hline MYT2 & Kim et al. 1998 \\
\hline NF-кB repressing factor NRF & Oumard et al. 2000 \\
\hline AML1/RUNX1 & Pozner et al. 2000 \\
\hline Gtx homeodomain protein & Chappell et al. 2000a \\
\hline \multicolumn{2}{|l|}{ Oncogenes } \\
\hline $\mathrm{c}-\mathrm{myc}$ & $\begin{array}{l}\text { Nabru et al. 1997; Stoneley et } \\
\text { al. } 1998\end{array}$ \\
\hline Pim-1 & Johannes et al. 1999 \\
\hline Protein kinase $\mathrm{p} 58^{\mathrm{PITSLRE}}$ & Cornelis et al. 2000 \\
\hline \multicolumn{2}{|l|}{ Transporters/receptors } \\
\hline $\begin{array}{l}\text { Cationic amino acid } \\
\text { transporter Cat-1 }\end{array}$ & Fernandez et al. 2001 \\
\hline Nuclear form of Notch 2 & Lauring and Overbaugh 2000 \\
\hline \multicolumn{2}{|l|}{ Translation factors } \\
\hline $\begin{array}{l}\text { Eukaryotic initiation factor } \\
4 \mathrm{G}(\mathrm{elF} 4 \mathrm{G})^{\mathrm{a}}\end{array}$ & Gan and Rhoads 1996 \\
\hline $\begin{array}{l}\text { Eukaryotic initiation factor } \\
4 \mathrm{Gl}(\mathrm{elF} 4 \mathrm{Gl})^{\mathrm{a}}\end{array}$ & Johannes and Sarnow 1998 \\
\hline $\begin{array}{l}\text { Death-associated protein } 5 \\
\text { (DAP5) }\end{array}$ & Henis-Korenblit et al. 2000 \\
\hline \multicolumn{2}{|l|}{ Activators of apoptosis } \\
\hline $\begin{array}{l}\text { Apoptotic protease } \\
\text { activating factor Apaf-1 }\end{array}$ & Coldwell et al. 2000 \\
\hline \multicolumn{2}{|l|}{$\begin{array}{l}\text { Dendritically localized } \\
\text { proteins }\end{array}$} \\
\hline $\begin{array}{l}\text { Activity-regulated } \\
\text { cytoskeletal protein } \\
\text { (ARC) }\end{array}$ & Pinkstaff et al. 2001 \\
\hline $\begin{array}{l}\alpha \text { subunit of calcium } \\
\text { calmodulin-dependent } \\
\text { kinase II dendrin }\end{array}$ & Pinkstaff et al. 2001 \\
\hline $\begin{array}{l}\text { Microtubule-associated } \\
\text { protein } 2 \text { (MAP2) } \\
\text { neurogranin (RC3) }\end{array}$ & Pinkstaff et al. 2001 \\
\hline \multicolumn{2}{|l|}{ Others } \\
\hline $\begin{array}{l}\text { Immunoglobulin heavy } \\
\text { chain binding protein } \\
\text { (BiP) }\end{array}$ & Macejak and Sarnow 1991 \\
\hline La autoantigen & Carter and Sarnow 2000 \\
\hline $\begin{array}{l}\beta \text { subunit of mitochondrial } \\
\mathrm{H}^{+}-\mathrm{ATP} \text { synthase }\end{array}$ & Izquierdo et al. 2000 \\
\hline Ornithine decarboxylase & Pyronnet et al. 2000 \\
\hline
\end{tabular}

${ }^{a}$ mRNAs contain different $5^{\prime}$ noncoding regions.

Listed are IRES elements that passed at least two tests when located in the intergenic region in a dicistronic mRNA: IRES is intact after translation in a cell-free system or in cultured cells expressing the dicistronic gene. IRES-mediated translation of the second cistron is independent of the translation of the first cistron.

(IRES) internal ribosomal entry site. 
The mechanism of initiation on picornavirus IRESS: the EMCV paradigm

The picornavirus IRES elements are divided into two major groups by sequence and structural similarities (Pilipenko et al. 1989a,b). One group contains EMCV, FMDV, and Theiler's murine encephalomyelitis virus (TMEV), and the other group contains poliovirus and rhinovirus. A third minor group contains hepatitis A virus (HAV). Sequence variation within a group can exceed $50 \%$, but many substitutions are covariant, resulting in conservation of secondary structure (Jackson and Kaminski 1995). Mutations that disrupt the integrity of structural elements or of conserved sequence motifs can cause general or cell type-specific loss of IRES function. These properties of picornavirus IRESs are also characteristic of all other major IRES groups discussed below.

The ribosomal entry sites on various picornavirus IRESs have been mapped. All picornavirus IRESs contain an AUG triplet at their 3' border, 25 nucleotides downstream from the beginning of a pyrimidine-rich tract. In EMCV and TMEV (GDVII strain), this AUG triplet is the initiation codon and ribosomes bind directly to it without scanning (Kaminski et al. 1990, 1994; Pilipenko et al. 1994). In FMDV, initiation occurs at this AUG triplet but also, more frequently, at the next downstream AUG triplet (Sangar et al. 1987). Very little initiation occurs at the AUG at the 3' border of the poliovirus IRES and the initiation codon is $\sim 160$ nucleotides downstream from it. The mechanism by which ribosomal subunits reach the start codon is not known. It could involve scanning or shunting of subunits to the initiation codon from the $3^{\prime}$ border of the IRES, or IRES-mediated loading of the ribosome onto the mRNA anywhere between the 3 ' border of the IRES and the initiation codon, followed by scanning (Belsham 1992; Hellen et al. 1994; Pestova et al. 1994; Ohlmann and Jackson 1999).

The minimum set of factors required for recruitment of the 40S subunit to the EMCV initiation codon has been determined by biochemical reconstitution of this process (Pestova et al. 1996a,b). The formation of $48 \mathrm{~S}$ complexes (i.e., binding of $43 \mathrm{~S}$ to the mRNA) is ATPdependent and requires the same factors as the $5^{\prime}$ enddependent initiation mechanism except that there is no requirement for eIF4E, PABP, or large $\mathrm{N}$-terminal and C-terminal fragments of eIF4G (Fig. 1). Specifically, the cap-binding protein complex eIF4F can be replaced by a complex of eIF4A and the central domain of eIF4G, eIF4G697-949 (Lomakin et al. 2000). Both eIF4A and the function of the central domain of eIF4G are essential for 48S complex formation (Fig. 1), exemplified by the profound inhibition of EMCV translation by dominantnegative mutant forms of eIF4A, which sequester the eIF4A/4G complex in an inactive form (Pause et al. 1994b). Recent data indicate that eIF4A plays its role in initiation on this IRES as part of a complex with eIF4G rather than as a singular polypeptide (Lomakin et al. 2000). Together, eIF2, eIF3, eIF4B, and 4G/4A promote $48 \mathrm{~S}$ complex formation equally at $\mathrm{AUG}_{834}$, the authentic initiation codon, and at $\mathrm{AUG}_{826}$, which is virtually un-
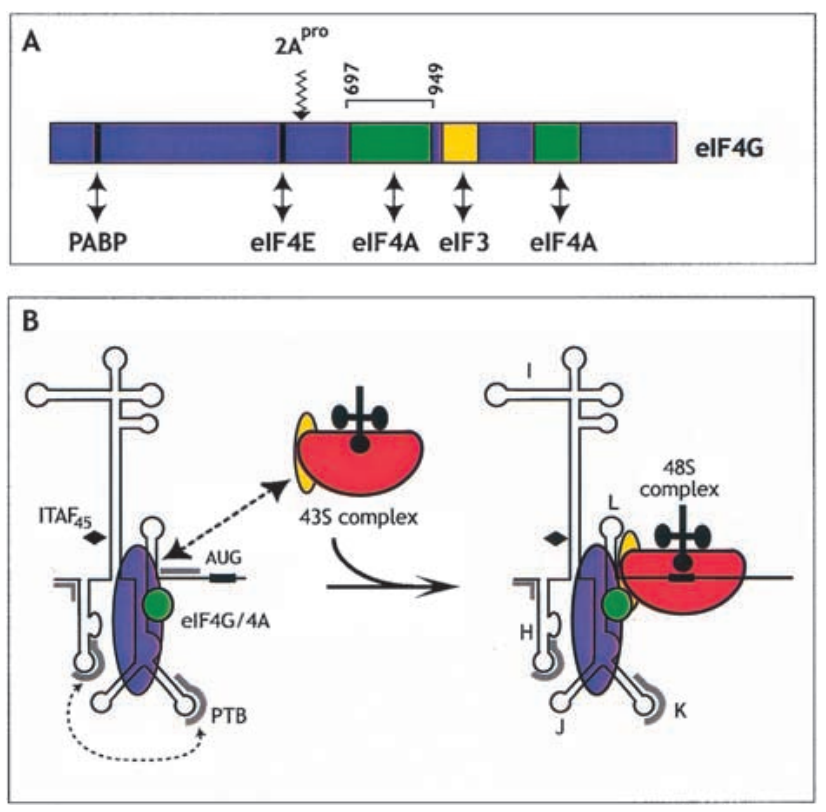

Figure 1. (A) Schematic diagram of human eIF4G1 protein. Shown are the binding sites for PABP, eIF4E, eIF4A, and eIF3 and the target site for picornaviral proteinase $2 \mathrm{~A}^{\text {pro }}$. The minimum eIF4G1 fragment that binds specifically to the EMCV IRES and supports $48 \mathrm{~S}$ complex formation corresponds to amino acid residues 697-949. (B) Model for assembly of 48S complexes on EMCV-like IRESs. Structural domains of the IRES and regions of contact with the following factors as determined by footprinting are shown: eIF4G/4A complex (blue/green), ITAF 45 (diamonds), PTB (gray). PTB contains four RRM domains and binds multiple sites on EMCV-like IRESs; such binding (indicated by a dotted line) therefore may stabilize a specific conformation of the IRES. The recruitment of a 40S ribosomal subunit (red) carrying initiator tRNA and eIF3 (yellow) is shown. See text for details.

used in vivo. Remarkably, eIF1 promotes dissociation of the ribosomal complex at $\mathrm{AUG}_{826}$, consistent with the previously noted function of this factor in enhancing the fidelity of initiation codon selection (Pestova et al. 1998a).

The essential eIF4G697-949/4A core of eIF4F binds specifically to the JK domain of the EMCV IRES, upstream of the initiation codon, and this interaction is necessary for initiation (Fig. 1; Pestova et al. 1996b; Kolupaeva et al. 1998). The structure of the central domain of eIF4G recently has been solved by X-ray crystallography, revealing a crescent-shaped domain that contains five $\alpha$-helical HEAT-repeats (Marcotrigiano et al. 2001). The identification of adjacent, partially overlapping binding sites for eIF4A and the EMCV IRES on this domain of eIF4G is consistent with the enhancement by eIF4A of eIF4G's affinity for the IRES (Lomakin et al. 2000).

It is not known whether the requirement for eIF4A and ATP reflects a requirement for local unwinding of mRNA near the initiation codon or structural rearrangement of subdomains of the IRES to allow ribosomal attachment. The eIF4G/4A complex likely also recruits 
other eIFs to the IRES such as eIF4B and eIF3 (Meyer et al. 1995; Pestova et al. 1996b; Lomakin et al. 2000). Although it is likely that these interactions contribute to promoting ribosomal attachment to the IRES, details of the mechanism by which ribosomal loading occurs are not known. Note also that the model depicted in Figure 1 does not invoke a role for the 230 nucleotide domain I of the EMCV IRES, which plays an unknown but essential role in initiation. It is possible that this domain makes weak contacts with eIF3 or even the 40 S subunit that so far have escaped detection.

Similar reconstitution experiments have not been conducted to determine the canonical factors required for initiation on poliovirus or rhinovirus IRESs. A requirement for the eIF4G/eIF4A complex is strongly suggested for the poliovirus IRES by the strong inhibition of the IRES by the dominant-negative form of eIF4A and by the insensitivity to the overexpression of eIF4E-binding proteins, causing sequestration of eIF4E (Pause et al. 1994b). Curiously, both the poliovirus and rhinovirus IRESs are stimulated to a much greater extent by cleavage of eIF4G by picornaviral proteases than the EMCV and FMDV IRESs (Hambidge and Sarnow 1992; Borman et al. 1995). The reason for this difference is not known. Remarkably, the activity of the HAV IRES is strongly reduced by cleavage of eIF4G, but can be restored by addition of eIF4F to in vitro translation reactions (Whetter et al. 1994; Borman and Kean 1997). Infection of cells by HAV does not lead to cleavage of eIF4G, and it therefore is possible that the HAV IRES differs from EMCV-like and poliovirus-like IRESs in that it has not acquired the ability to function when eIF4G is cleaved.

Although PABP is not necessary for the formation of 48S/EMCV IRES complexes, it enhances EMCV IRESmediated initiation and, to a much greater extent, poliovirus IRES-mediated initiation on mRNAs with 3' polyadenosine tails (Bergamini et al. 2000; Michel et al. 2000). These findings may indicate a function for PABP in IRES-mediated initiation independent of its interaction with the $\mathrm{N}$ terminus of eIF4G.

\section{Cellular RNA-binding proteins that stimulate picornavirus IRES elements}

The activity of several picornavirus IRESs is subject to cell type-specific restriction. For example, the attenuated neurovirulence of Sabin vaccine strains of poliovirus is in large part due to a defect in translation initiation in neuronal cells caused by substitutions in the IRES (Svitkin et al. 1985; Stewart and Semler 1998). It is possible that a noncanonical translation initiation factor that is required for IRES-mediated initiation is limiting in neurons. This hypothesis is consistent with observations that translation mediated by poliovirus and rhinovirus IRESs is also very weak in rabbit reticulocyte lysates (RRL) but can be enhanced by addition of the ribosomal salt wash fraction from HeLa cells (e.g., Brown and Ehrenfeld 1979). Initiation mediated by these, and possibly other, IRESs therefore requires IRES trans-acting factors (ITAFs) that are either absent in RRL or significantly less abundant in RRL than in permissive cells. Ultraviolet cross-linking assays initially were used to identify IRES-binding proteins, but it has become apparent that proteins can bind specifically to an IRES yet play no role in promoting initiation on it, so that confirmation of a role in IRES-mediated initiation for a suspected ITAF requires a direct functional assay. A handful of ITAFs have been discovered in recent years that play important roles in modulating the efficiencies of various picornaviral IRES elements.

The pyrimidine tract-binding protein (PTB) contains four RNA recognition motif-like domains and binds to all picornavirus IRESs, most likely to noncontiguous sites on each, as has been determined for EMCV and FMDV by footprinting (Kolupaeva et al. 1996; Pilipenko et al. 2000). Translation initiation on the wild-type EMCV IRES was enhanced less than twofold by PTB (Pestova et al. 1996a; Kaminski and Jackson 1998), but the PTB dependence of initiation was significantly increased either by a single adenosine nucleotide insertion in the eIF4G-binding site in the IRES or by alteration of the coding sequence adjacent to the initiation codon (Kaminski and Jackson 1998). The interaction of PTB with the EMCV IRES was not affected by these changes. These observations are more consistent with a model in which ITAFs such as PTB bind the IRES (Fig. 1) and help it to attain or maintain an active conformation in which it is able to bind essential factors and the 43S complex in a productive manner rather than, for example, recruiting them directly (Kaminski and Jackson 1998).

Very recently, a novel ITAF was discovered that influenced the binding of the eIF4G/4A complex to the FMDV IRES. The TMEV (GDVII strain) and the FMDV (01K) IRESs are $\sim 40 \%$ identical and are closely related to the EMCV IRES. Initiation on all three IRESs involves binding of the eIF4G/4A complex to the J-K domain (see Fig. 1). However, initiation on the TMEV IRES was strongly dependent on PTB and initiation on the FMDV IRES required both PTB and a 45-kD ITAF (ITAF45) that is expressed in proliferating cells (Pilipenko et al. 2000). PTB and ITAF45 bound to nonoverlapping sites on the FMDV IRES and together caused both localized RNA conformational changes adjacent to the eIF4G/4A-binding site and enhanced binding of eIF4G/4A to the IRES. The EMCV, FMDV, and TMEV IRESs all bind to both PTB and ITAF45, but only the FMDV IRES requires ITAF45 for function. Therefore, functional requirement for ITAFs by certain IRESs rather than the ability of the ITAFs to bind to the IRES is important for their role in IRES efficiency. Significantly, the neurovirulent GDVII strain of TMEV can be completely attenuated by substituting its IRES with FMDV $\mathrm{O}_{1} \mathrm{~K}$ IRES even though growth of the chimeric virus in nonneuronal BHK cells was not impaired (Pilipenko et al. 2000). Differences in the expression of ITAF45 in neurons and in proliferating nonneuronal cells could explain the failure of the chimeric virus containing the FMDV IRES to grow in murine brain cells. 
Last, we briefly discuss three ITAFs that regulate the poliovirus and rhinovirus IRESs. It has been known for a long time that the nuclearly located $\mathrm{La}$ autoantigen binds to the poliovirus IRES, stimulates its activity in vitro, and enhances the accuracy of initiation codon selection; however, these effects required concentrations of La far above those present in HeLa cell extracts (Meerovitch et al. 1993). Recently, it has been reported that the La autoantigen is cleaved by a virus-encoded protease in virally infected cells and that the IRES stimulatory fragment of $\mathrm{La}$ is retained in the cytoplasm in infected cells (Shiroki et al. 1999). Thus, it is possible the ITAF-containing fragment of La exists in infected cells at a higher local intracellular concentration than was assumed previously.

In a second line of investigation, biochemical fractionation of HeLa cytoplasmic lysates was used to identify ITAFs that synergistically stimulate the rhinovirus IRES. This study resulted in the identification of PTB as well as a complex between the unr (upstream of $N$-ras) protein and an associated WD-repeat protein (unrip; Hunt et al. 1999). Curiously, neither unr nor the unr/ unrip complex stimulated the poliovirus IRES.

Finally, the poliovirus IRES is greatly stimulated by poly $(\mathrm{rC})$ binding protein-2 (PCBP-2); curiously PCBP-2 binds both to the viral IRES and the 5 ' terminal cloverleaf-type structure that is an important signal in viral RNA replication (Blyn et al. 1996, 1997; Gamarnik and Andino 1997; Walter et al. 1999; Gamarnik and Andino 2000). It is not yet apparent whether the requirement for PTB and PCBP-2 for poliovirus translation can begin to provide an explanation for the attenuated neurovirulence of Sabin strains of poliovirus. Like PTB, PCBP-2, and unr also contain multiple RNA-binding domains and therefore have the potential to make multipoint interactions with IRESs to stabilize their folding into an active conformation. Overall, these findings suggest that the poliovirus/rhinovirus and EMCV/FMDV/TMEV IRESs display a diversity in sequence and structure that can lead to specific requirement for a variety of ITAFs. These specific requirements could lead to differential IRES regulation.

\section{Initiation of translation by factor-independent binding of ribosomes to the hepatitis $C$ virus IRES}

A landmark discovery in the eukaryotic translation field was the finding that the hepatitis $\mathrm{C}$ virus (HCV) IRES can bind $40 S$ subunits in the absence of any eIF, including the eIF2/GTP/initiator tRNA ternary complex. Remarkably, toeprinting experiments showed that the AUG initiation codon is positioned at or near the P site of the bound 40S subunits (Fig. 2; Pestova et al. 1998b). Together with the recent cryo-electron microscopic reconstruction at $20 \AA$ resolution of 40 S/HCV IRES complexes (Spahn et al. 2001), these findings have provided a spectacular insight into molecular interactions that take place in an IRES-40S complex. We describe and discuss these major findings in the following sections.

\section{Comparison of IRES elements between HCV and related flaviviruses}

The 5' NTRs of HCV and the related classical swine fever virus (CSFV), bovine viral diarrhea virus (BVDV), and GB virus B (GBV-B) all promote internal initiation of translation (Tsukiyama-Kohara et al. 1992; Wang et al. 1993; Poole et al. 1995; Rijnbrand et al. 1997, 2000; Grace et al. 1999). These 5' NTRs contain IRESs that are 330-390 nucleotides in length and have related structures, even though their sequences differ significantly from one another (Lemon and Honda 1997). Sequence differences between the IRESs of different genotypes of any one of these viruses consist mostly of compensatory nucleotide changes within structural elements that serve to maintain base pairing (e.g., Smith et al. 1995). As in the picornavirus IRESs, mutations that disrupt helical regions in HCV-like IRESs can substantially reduce their initiation activity, but this can be restored by compensatory second-site mutations (Rijnbrand et al. 2000). These observations are consistent with a model for IRES function in which helices form a structural scaffold to orient conserved unpaired regions that act as binding sites for factors and ribosomes so that they can assemble functional initiation complexes.

\section{Structural features of the HCV IRES}

Mutagenesis studies combined with biochemical probing analysis revealed that the HCV IRES consists of three major structural domains (II, III, and IV) radiating from a complex pseudoknot (Fig. 2). Reconstructions of the IRES at $\sim 20 \AA$ resolution produced by cryo-electron microscopy have shown that these domains form an extended structure in which the pseudoknot and domain IV are centrally located (Spahn et al. 2001).

Domain I comprises the extreme $5^{\prime}$ end of the $5^{\prime}$ NTR and is not part of the IRES. Domain II contributes significantly to IRES function, but deletion of this domain does not lead to complete loss of activity (TsukiyamaKohara et al. 1992; Reynolds et al. 1996; Kolupaeva et al. 2000a,b). Domain III contains several essential elements, including a large four-way junction (IIIabc) and two smaller stem-loop structures (IIId and IIIe). The structures of IIId and IIIe have been solved by NMR spectroscopy (Klinck et al. 2000; Lukavsky et al. 2000). Subdomain IIId contains an internal asymmetric E-loop motif (Klinck et al. 2000; Lukavsky et al. 2000) that is also present in the sarcin/ricin loop in 28S rRNA (Correll et al. 1998; Seggerson and Moore 1998). In the HCV IRES, this E-loop motif contains two unusual S-turns involving GAGU $_{256-259}$ and GGUC $_{267-270}$, located on the same site of the hairpin, presenting a unique feature of a narrowed major groove and a distorted phosphodiester backbone. By analogy with the sarcin/ricin loop, the HCV E-loop may be involved in interactions with other IRES sequences or components of the 40S subunit (Klinck et al. 2000; Lukavsky et al. 2000). Subdomain IIIe adopts a novel tetraloop fold in which the loop bases of the A296 and U297 point toward the major groove and thus are 


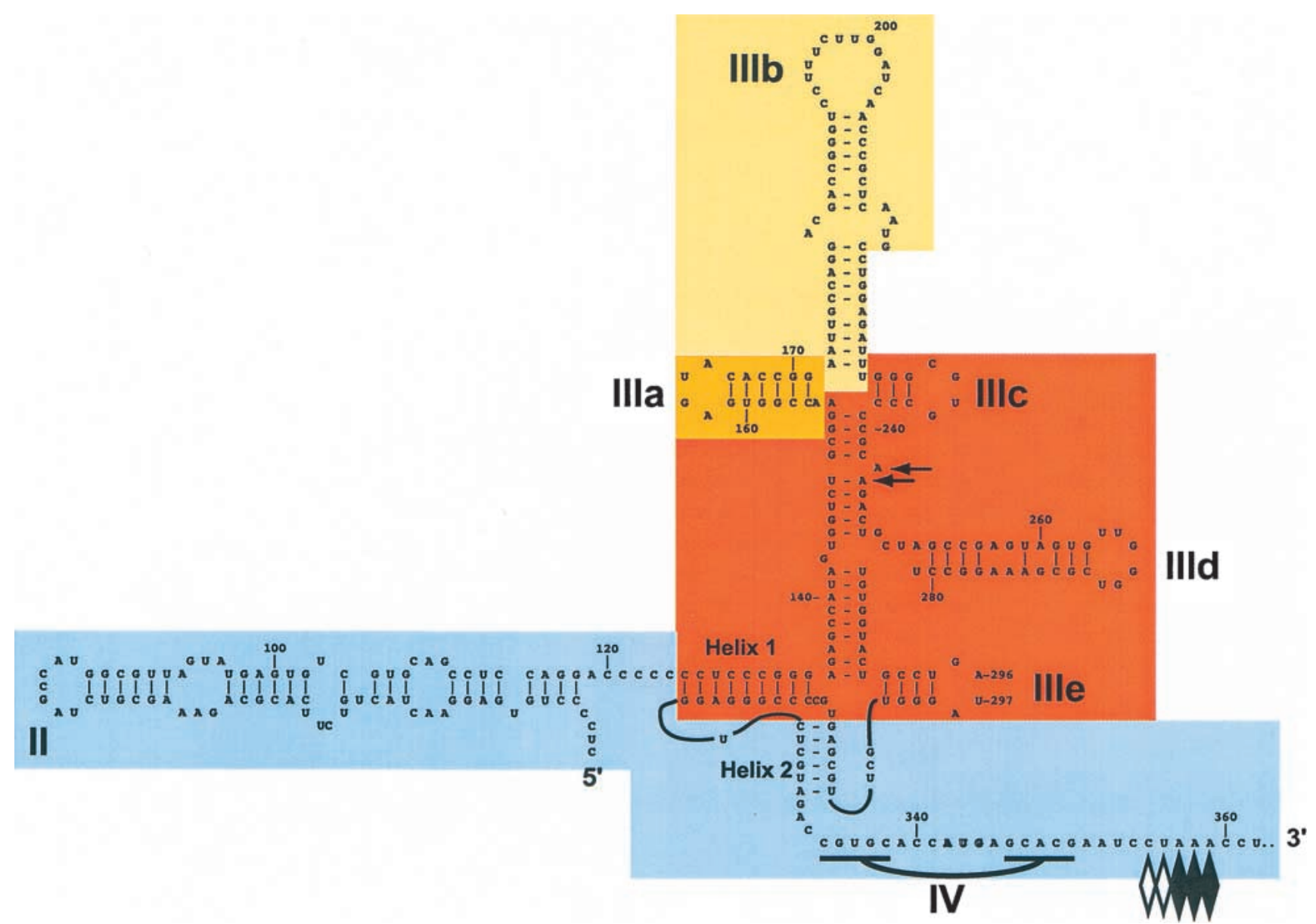

Figure 2. Protein-RNA interactions on the HCV IRES. The secondary structures of domains II, III, and IV of the HCV IRES are shown schematically (adapted from Honda et al. 1999). Binding sites for eIF3 (yellow) and 40S subunits (red) are shown. A subdomain that is required for binding of eIF3 and the 40S subunit is shown in orange, and elements of the IRES that interact with $40 \mathrm{~S}$ subunits and are required for accurate placement of the coding region in the decoding site of the $40 \mathrm{~S}$ subunit are colored light blue. The toeprints detected at the leading edge of bound eIF3 are indicated by arrows. The toeprints at the leading edge 40S subunits in binary IRES/40S subunit complexes are indicated by unfilled diamonds; toeprints formed on eIF2/GTP/Met-tRNA $\mathrm{i}_{\mathrm{i}} / 40 \mathrm{~S}$ subunits are indicated by filled diamonds.

exposed and not in contact with the RNA backbone (Lukavsky et al. 2000).

Domain IV contains the initiation codon and is basepaired in the HCV and GBV-B IRESs, but not in those from BVDV or CSFV. HCV coding sequences per se are not essential for internal initiation, because they can be replaced completely by heterologous sequences (Tsukiyama-Kohara et al. 1992; Wang et al. 1993). However, there has been some controversy as to whether HCV sequences located downstream from the initiation codon influence the efficiency of IRES-mediated initiation (Reynolds et al. 1995; Lu and Wimmer 1996). If one considers that ribosomal entry occurs at the initiation codon without prior scanning (Reynolds et al. 1996; Rijnbrand et al. 1997), and that mutations in the IRES that stabilize structures containing the initiation codon inhibit ribosomal attachment and consequently IRES-mediated initiation (Honda et al. 1996; Myers et al. 2001), it then seems likely that the negative influence of some heter- ologous coding sequences on IRES function may be because they interfere sterically with ribosomal attachment.

\section{HCV IRES can recruit $40 S$ subunits without any eIF}

Biochemical reconstitution of the initiation process on $\mathrm{HCV}$, CSFV, and BVDV IRESs has revealed that it occurs by a mechanism that differs fundamentally from initiation on EMCV-like IRESs (Pestova et al. 1998b; Pestova and Hellen 1999). The 40S subunit binds specifically and stably to the HCV-like IRESs without any requirement for initiation factors, in such a way that the ribosomal $\mathrm{P}$ site is placed in the immediate proximity of the initiation codon (Pestova et al. 1998b). Subsequent addition of the ternary eIF2/GTP/initiator tRNA complex to IRES/ $40 S$ subunit complexes is necessary and sufficient for formation of $48 \mathrm{~S}$ complexes in which the anticodon of initiator tRNA is base-paired with the initiation codon. 
This base pairing is associated with the appearance of three new toeprints (Fig. 2, filled diamonds) immediately downstream from those detected for binary IRES/40S subunit complexes (Fig. 2, open diamonds).

Although eIF3 is not needed for 48S complex formation, it binds specifically to these IRESs and is likely to be a constituent of 40S/IRES complexes in vivo. Human eIF3 has a molecular mass of $\sim 600 \mathrm{kD}$ and contains at least 11 subunits; four of these interact directly with the IRES (Sizova et al. 1998), but it is not yet known which subunit(s) are primary determinants of this interaction. The binding site for eIF3 has been mapped by toeprinting and footprinting to the terminal half of domain III (Fig. 2; arrows; Buratti et al. 1998; Pestova et al. 1998b; Sizova et al. 1998; Pestova and Hellen 1999; Odreman-Macchioli et al. 2000; Kieft et al. 2001). The role eIF3 in HCV IRES translation is not yet known. eIF3 may destabilize incorrectly assembled 48S complexes (Kolupaeva et al. 2000b) and play a role in stages in initiation after $48 \mathrm{~S}$ complex formation (Pestova et al. 1998b). The independent interaction of eIF3 and eIF2/GTP/initiator tRNA with the HCV-like IRESs is likely to enhance the affinity and specificity of binding and to stabilize the resulting $48 \mathrm{~S}$ IRES/mRNA complexes.

Significantly, initiation on HCV-like IRESs has no requirement for ATP or any factor associated with ATP hydrolysis, including eIF4A, eIF4B, or eIF4F, and is resistant to inhibition by dominant negative eIF4A mutants (Pestova et al. 1998b; Pestova and Hellen 1999). Indeed, these eIFs probably are unable to gain access to the region flanking the initiation codon of HCV-like IRESs to which ribosomes bind. Certainly, RNA unwinding by eIF4A is not observed, because initiation on these IRESs is repressed by local secondary structures in this region that would be readily unwound during cap-mediated initiation (Honda et al. 1996; Myers et al. 2001). Several other proteins such as La, PTB, and hnRNPL interact with the HCV IRES (Ali and Siddiqui 1995, 1997; Hahm et al. 1998), but they are not essential for 48S complex formation in vitro. Evidence for the involvement of PTB in HCV IRES-mediated translation initiation has been disputed by experiments conducted in RRL depleted of PTB (Kaminski et al. 1995). However, it is possible that isoforms of PTB may enhance the HCV IRES in cultured cells (Anwar et al. 2000; Gosert et al. 2000).

\section{A prokaryotic-like mode of $40 S$ recruitment to the HCV-like IRESS}

The principal difference between initiation on HCV-like IRESs from all previously characterized modes of initiation is the ability of these IRESs to bind directly to $40 \mathrm{~S}$ subunits in such a way that the initiation codon is placed directly in the ribosomal decoding region. This ability enables initiation on these IRESs to dispense with a requirement for several canonical factors including eIF4A, eIF4B, and eIF4F.

Although there are analogies between factor-independent binding of $30 \mathrm{~S}$ ribosomal subunits to Shine-Dalgarno sequences in prokaryotic mRNAs (Shine and Dal- garno 1975) and factor-independent binding of $40 \mathrm{~S}$ eukaryotic subunits to HCV-like IRESs, there are also significant differences. Toeprinting and deletion analyses indicated that $40 \mathrm{~S}$ subunits bind to multiple noncontiguous RNA sequences in these IRESs rather than to a single linear sequence such as the prokaryotic ShineDalgarno sequence. Furthermore, the discrete 40S binding sites are not close together in the folded RNA structure; therefore, ribosomal attachment involves multiple sites on the 40S subunit (Pestova et al. 1998b; Pestova and Hellen 1999).

Cryo-electron microscopy analysis reveals an intricate network of 4OS/HCV IRES interactions

Recent results obtained by Spahn and colleagues using cryo-electron microscopic analysis of 40S/HCV IRES complexes have yielded exciting new insights into the structure of the 40S/HCV IRES complex (Spahn et al. 2001). First, the IRES assumes a single conformation when bound to the $40 S$ subunit. Second, the 40 S subunit makes numerous contacts with the IRES. Specifically, the IRES binds to the solvent side of the 40S subunit near the channel through which mRNA exits the ribosome, such that domain IIIb is positioned close to the site on the $40 \mathrm{~S}$ subunit to which eIF3 binds. Third, domain II loops out from the $40 \mathrm{~S}$ surface and the region of contact partially overlaps the exit (E) site of the ribosome, normally occupied by deacylated tRNA before it detaches from the ribosome. Excitingly, association of the HCV IRES with $40 \mathrm{~S}$ induces a dramatic conformational change in the $40 \mathrm{~S}$ subunit. This change is dependent on domain II. The positions of the observed changes on $40 \mathrm{~S}$ indicated the altered $40 \mathrm{~S}$ may function as a clamp that helps to hold the coding mRNA in the decoding cleft (Spahn et al. 2001). Such changes are consistent with the reduced intensity of $40 \mathrm{~S}$ toeprints associated with mRNA bound in this cleft when domain II of HCV and CSFV were removed (Kolupaeva et al. 2000a,b).

Positioning of initiation-competent 40 S subunits to
the HCV IRES occurs in at least two separable steps

The functional importance of these observed sites of ribosomal interaction in recruiting $40 \mathrm{~S}$ subunits to the initiation codon are supported by the results of extensive mutational analyses (Pestova et al. 1998b; Kieft et al. 1999, 2001; Jubin et al. 2000; Kolupaeva et al. 2000a,b; Lukavsky et al. 2000). Toeprinting of 40S subunits bound to CSFV and HCV IRESs has shown that they contain one set of determinants that is required for initial ribosomal attachment, and a second set of determinants that promotes accurate placement of the initiation codon in the ribosomal $\mathrm{P}$ site. The set of determinants required for ribosomal attachment includes the apical residues GGG $_{266-268}$ in HCV IIId and analogous residues in CSFV IIId1, and the $5^{\prime}$ proximal helix 1 of the pseudoknot. In contrast, helix 2 of the pseudoknot is not required for ribosomal binding, but substitutions in this helix impair 
binding of $40 S$ to sequences flanking the initiation codon in the mRNA-binding cleft. Similarly, deletion of domain II and substitutions or deletions in subdomain IIIa did not impair the formation of binary IRES/40S subunit complexes but also impaired binding of the initiation codon region to the ribosomal mRNA-binding cleft. The observation that the initiation codon region can be deleted without impairing ribosomal attachment to the IRES even though it constitutes a major site of interaction between these IRESs and the 40S subunit is consistent with the conclusion that ribosomal attachment occurs in at least two separable steps.

\section{Insect cricket paralysis-like viruses: initiation of translation without initiator tRNA}

That notion that RNA has the ability to function as a catalyst in a variety of biological reactions without the participation of proteins recently has entered the IRES field. Although eIF-independent formation of 40S/HCV IRES complexes was heretical, the recent discovery that IRES elements in cricket paralysis-like viruses cannot only perform eIF-independent formation of 40S/IRES complexes but do not need eIF2, initiator tRNA, eIF5B, or GTP hydrolysis to form an 80S/IRES complex has been astounding.

\section{The initiation codon-less IRES in cricket} paralysis-like viruses

The recent sequencing of several insect picorna-like RNA virus genomes, epitomized by cricket paralysis virus (CrPV) has revealed that they are dicistronic (for references see http://www.iah.bbsrc.ac.uk/virus/picornalike). The upstream open reading frame (ORF) that encodes the nonstructural protein precursor is separated by an intergenic region (IGR) from the downstream ORF encoding the structural protein precursor (Fig. 3). Translation of both ORFs is mediated by distinct IRESs (Sasaki and Nakashima 1999; Domier et al. 2000; Wilson et al. 2000b). Most interest has focused on the structurally conserved IGR IRES, 180 nucleotides in length, because nucleotide and protein sequence analyses have shown that the first encoded amino acid is not methionine and that initiation does not occur at a cognate AUG codon, or even a weak cognate codon such as CUG or GUG. The $\mathrm{N}$-terminal residue of the capsid protein precursor is either alanine (encoded by GCU or GCA) or glutamine (encoded by CAA). This coding triplet is immediately adjacent to an $\sim 42$ nucleotide pseudoknot that is essential for IRES function determined by mutations that disrupt (Fig. 3, mutant 1) or restored the pseudoknot (Fig. 3, mutant 2; Sasaki and Nakashima 1999; Domier et al. 2000; Wilson et al. 2000b). Nucleotides upstream of this domain may form an extensive triple-nested pseudoknot (Kanamori and Nakashima 2001). As in the other classes of IRES described above, helical regions of CrPV-like IRESs appear primarily to play a structural role: analysis of seven CrPV-like viral genomes has indicated that co- variant substitutions that maintain base pairing complementarity of helices have at most minor effects on IRES function. Most invariant nucleotides (shown in blue in Fig. 3) are located in unpaired loops and bulges in the triple pseudoknots and therefore may be involved in interactions with the ribosome.

\section{IGR-IRES mediate translation is methionine independent}

In a landmark study, Sasaki and Nakashima provided convincing evidence that the IGR-IRES in Plautia stali intestine virus (PSIV) mediates translation initiation at a glutamine-encoding CAA codon (Sasaki and Nakashima 2000). These authors showed that the PSIV IGR-IRES mediated translation of a protein lacking an N-terminal methionine residue; in clever control experiments, they excluded the possibility that methionine aminopeptidases removed the $\mathrm{N}$-terminal methionine residue on the newly synthesized proteins (Sasaki and Nakashima 2000). This finding raised the possibility that if translation initiation from PSIV IGR-IRES did not need an initiator tRNA methionine, perhaps it could dispense with the entire ternary eIF2/GTP/initiator tRNA complex for initiation.

The IGR-IRES can assemble 80S complexes without eIFs, position the initiation start codon in the ribosomal $A$ site, and translocate without formation of a peptide bond

Direct binding experiments showed that $40 \mathrm{~S}$ subunits can bind stably to the CrPV IGR-IRES in the absence of ternary complex or any other eIF. Toeprint analysis performed to determine the position of the ribosome on the IGR-IRES indicated that the first decoded triplet, GCU, was in the ribosomal A site with the preceding CCU triplet in the P site (Wilson et al. 2000a). The CCU triplet is not decoded and can be substituted by any codon, even with a stop codon, without effect on IRES function if the pseudoknot structure is maintained (Sasaki and Nakashima 1999; Wilson et al. 2000b).

Surprisingly, addition of purified 60S subunits to the 40S/IGR-IRES complexes resulted in the formation of 80S/IGR-IRES complexes without any requirement for eIF5, eIF5B, or hydrolysis of GTP. Furthermore, translation assays in RRL showed that the aminoacyl-tRNA is delivered to the empty ribosomal A site by elongation factor 1 (EF1), after which the 80S ribosome undergoes a pseudotranslocation (i.e., without formation of a peptide bond) moving the GCU codon to the ribosomal P site (Wilson et al. 2000a). This translocation event does not depend on prior peptide bond formation and is resistant to both the nonhydrolyzable GTP analog GMP-PNP and the elongation inhibitor cycloheximide, indicating that translocation does not involve the enzymatic activity of EF2. Pseudotranslocation depends on delivery of aminoacyl-tRNA to the A site, as it is inhibited by antibiotics such as sparsomycin (Wilson et al. 2000a). 80S ribosomes 

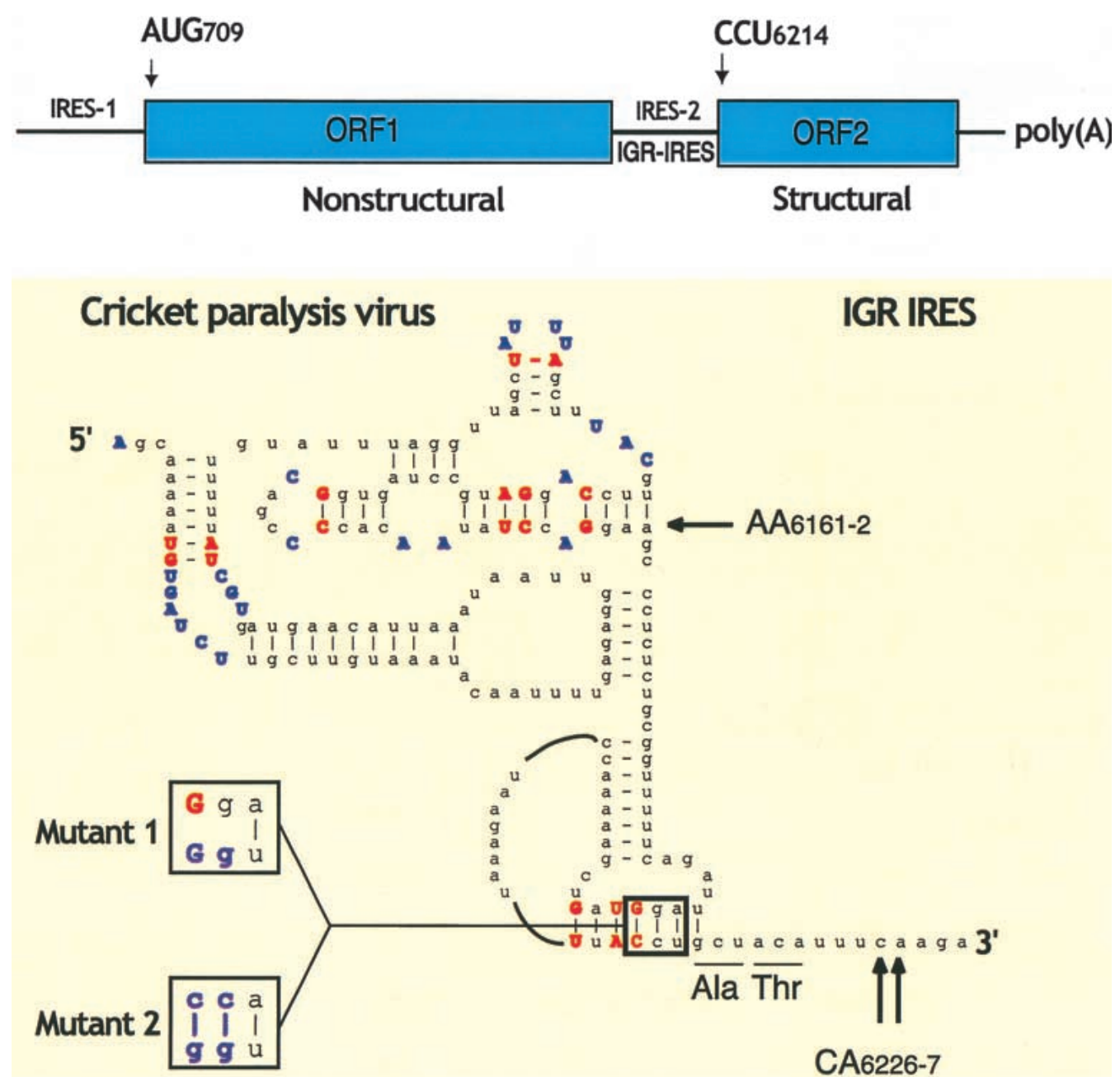

\begin{tabular}{lll} 
IRES & IRES activity & \multicolumn{1}{c}{ Toeprints } \\
wt & $100 \%$ & AA6161-2 + CA6226-7 \\
Mutant 1 & $<1 \%$ & AA6161-2 \\
Mutant 2 & $50 \%$ & AA6161-2 + CA6226-7
\end{tabular}

Figure 3. Features of the cricket paralysis virus (CrPV) IRES. A diagram depicting the genome structure of CrPV with its two IRES elements is shown on the top (see text for details). The predicted secondary structure of the CrPV IRES is remodeled after the Plautia stali intestine virus IRES (Kanamori and Nakashima 2001). Conserved base-paired and unpaired residues are shown in red and blue, respectively. The locations and genotypes of mutant 1 and mutant 2 are indicated. The bottom panel shows the IRES activities and toeprinting patterns in the mutated IRES elements.

therefore can move on the CrPV IGR-IRES in a way that has not been observed for any other mRNA. The mechanism by which translocation is induced has not yet been determined, but occupancy of the P site by the pseudoknot as well as other interactions of upstream elements of the IRES with the ribosome may potentiate ribosomal movement.

In examples discussed above, the EMCV IRES is able to bypass the requirement for eIF4E, and the HCV IRES does not require eIF4E, eIF4A, eIF4B, or eIF4F. The model 
for CrPV IRES function presented here indicates that it has eliminated the requirement for initiator tRNA and all initiation factors and is able to bind ribosomes and to induce them to enter the elongation phase of translation directly. There is no evidence that any cellular mRNAs use this mode of IRES-mediated initiation, but any that were to do so would be expected to be translated efficiently in circumstances in which eIF2-GTP is limiting, for example, by phosphorylation of eIF2. Indeed, it has been shown that the activity of the CrPV IRES is greatly enhanced during the induction of the unfolded protein response, a scenario that results in the phosphorylation of eIF2 (Wilson et al. 2000a).

\section{Properties of cellular IRES elements}

Although the list of cellular mRNAs containing IRES elements is growing (Table 3), little is known about the mechanism by which naturally occurring cellular IRES elements capture 40S subunits. On the other hand, substantial evidence has been accumulated that points to the translational regulation of IRES-containing mRNAs during the cell cycle and during various stress situations that can lead to cell death. We address these findings in the following sections.

\section{Cellular IRES elements can comprise multiple noncontiguous sequences that display IRES activity}

The structural features of cellular IRES elements remain largely unknown. Le and Maizel have predicted that a Y-shaped double-hairpin structure followed by a small hairpin constitutes an RNA motif that can be found upstream of the start site codon in a variety of cellular IRES elements (Le and Maizel 1997). However, there is no experimental evidence for a functional role for this motif in internal initiation.

As described above, IRES elements in viral RNA genomes contain higher ordered structures whose integrities are essential for IRES activity. Thus, it was surprising that the IRES elements in BiP (Yang and Sarnow 1997), vascular endothelial growth factor (Huez et al. 1998), and c-myc (Stoneley et al. 1998) contained several noncontiguous sequence elements that displayed IRES activities on their own. These findings have suggested that elusive SD-like sequences may exist in IRES elements and that they can be isolated by functional means from complex IRES elements. A series of experiments by Mauro and colleagues has substantiated this notion. First, Mauro and Edelman noted that many eukaryotic mRNAs contain rRNA-like sequences in both sense and antisense orientations in their NTRs, coding and intron sequences (Mauro and Edelman 1997). Next, a functional role for these rRNA-like sequences was examined in the mRNAs encoding ribosomal protein S15 (Tranque et al. 1998) and the homeodomain GTX (Hu et al. 1999), both of which contain several sequence motifs with complementarity to the $3^{\prime}$ end of $18 \mathrm{~S}$ rRNA. Crosslinking of these sequence to $40 \mathrm{~S}$ subunits could be accomplished and cell-free translation assays showed that the strength of the mRNA-rRNA interactions was correlated inversely with mRNA translation efficiency. Further examination of the 196-nucleotide 5' NTR of GTX revealed the presence of an IRES (Table 3) that could be dissected into four nonoverlapping RNA sequences, each displaying IRES activity (Chappell et al. 2000a). A ninenucleotide sequence element with complementarity to 18S rRNA also displayed IRES activity in the dicistronic assay that was approximately threefold over background; however, 10 linked copies of this mini-IRES stimulated second cistron translation by $\sim 500$-fold /Chappell et al. 2000a). The curious finding that the same nine nucleotide sequence element also can function as a translational repressor (see above) when present in the $5^{\prime}$ NTR of a capped monocistronic mRNA is puzzling. Although there is no immediate answer to explain this apparent discrepancy, it is known from studies on 40S/HCV IRES complexes that the translational efficiency of mutated IRES elements can vary greatly even when the binding affinity of 40S to the mutated IRES was unaffected (Kieft et al. 2001). Thus, events subsequent to 40S binding might dictate in some manner the efficiency of the IRES.

\section{Factors that regulate cellular IRES elements}

It is likely that the canonical eIFs that recruit $40 \mathrm{~S}$ subunits to picornaviral IRES elements are used in the recruitment of $40 S$ subunits to most cellular IRES elements. However, besides the report that overexpression of eIF4G in cultured cells stimulated both cap-dependent translation as well as the IRES present in ornithine decarboxylase (Hayashi et al. 2000) nothing is known about the role of canonical eIFs in internal initiation.

The role of noncanonical ITAFs only recently has been explored for cellular IRES elements. Elroy-Stein and colleagues provided evidence that a phosphorylated form of hnRNP C interacts with the differentiation-induced IRES in PDGF2 mRNA (Table 3; Sella et al. 1999). Similarly, Holcik and colleagues found that the La autoantigen stimulated the IRES in X-linked inhibitor of apoptosis mRNA (Holcik and Korneluk 2000). Jang and collaborators showed that PTB inhibits the BiP IRES (Table 3) both in vitro and in cultured cells (Kim et al. 2000), suggesting that PTB can be both a negative and a positive (for the picornaviral IRESs) ITAF. More recently, Mitchell and colleagues showed that the activity of the Apaf-1 (apoptotic protease-activating factor 1) IRES was activate $\bar{d}$ in rabbit reticulocyte lysates supplemented with PTB and unr (Mitchell et al. 2001). Similarly, Apaf-1 IRES activity was enhanced in cell lines deficient in these ITAFs after overexpression of PTB and unr. Moreover, this IRES bound unr, but bound PTB only in the presence of unr (Mitchell et al. 2001). From what is known about initiation on EMCV-like IRESs, ITAFs therefore likely exert their function on cellular IRESs as chaperones that aid in the folding of RNA motifs.

Although the auxiliary roles of ITAFs is unclear, it is intriguing that some of the ITAFs such as PTB, La, and hnRNPC can shuttle between the nucleus and cyto- 
plasm during the cell cycle (Ghetti et al. 1992) and in poliovirus-infected cells (Gustin and Sarnow 2001), indicating that they may regulate the activity of IRES elements at particular stages of the cell cycle, during apoptosis or during viral infection.

A striking property of many cellular IRESs is that their activity shows strong cell type-specific variation and in some instances is developmentally controlled (Ye et al. 1997; Creancier et al. 2000; Stoneley et al. 2000b). The inability of an IRES to mediate initiation in specific cells or under specific physiological conditions could be due to the positive or negative regulatory ITAFs that influence IRES function but not cap-mediated initiation.

\section{Growth regulatory genes and gene transcribed in response to stress contain IRES elements}

To identify mRNAs that require reduced concentrations of intact cap-binding complex eIF4F, the polyribosomal association of mRNAs was examined by a cDNA microarray in poliovirus-infected cells at a time when both isoforms of eIF4G were significantly proteolyzed (Johannes et al. 1999). This analysis was expected to reveal classes of mRNAs that were simply overexpressed as a consequence of viral infection, in which translational elongation rates were slowed, that required low concentrations of intact eIF4F such as the shunting-promoting late leader of adenovirus (see above), or that contained IRES elements. Approximately $3 \%$ of the mRNAs examined remained on polysomes in infected cells; some of those have been shown to harbor IRES elements (Table 3). These IRES-containing mRNAs encode proteins that are produced as a response to a variety of stress situations, such as inflammation, angiogenesis, and response to serum (Johannes and Sarnow 1998; Johannes et al. 1999). Although these studies have the caveat of being performed in virus-infected cells, it is noteworthy that some of the IRES-containing mRNAs were identified by different experimental approaches as well. For example, the c-myc IRES has been shown to be active both during mitosis (Pyronnet et al. 2000) and during the induction of apoptosis (Stoneley et al. 2000a).

\section{Regulation of IRES elements during cell growth and programmed cell death}

It is known that global cellular protein synthesis is regulated during the $\mathrm{G}_{2} / \mathrm{M}$ phase of the cell cycle (Bonneau and Sonenberg 1987; Huang and Schneider 1991) during programmed cell death (for review, see Holcik et al. 2000) and during a variety of stress situation such as nutritional deprivation, heat shock, or the unfolded protein response (for review, see Kaufman 1999). Declines in overall protein synthesis has been found to correlate with the inactivation of certain eIFs. Thus, it was of interest to test whether IRES-mediated translation was refractory to translation inhibition in these circumstances, especially in cases when the activity of eIF4F was diminished.
Certain viral and cellular IRES elements are active during the $G_{2} / M$ phase of the cell cycle

The eIF4E subunit of eIF4F is dephosphorylated during the $G_{2} / M$ phase of the cell cycle, correlating with diminished cap-dependent translation (Bonneau and Sonenberg 1987; Huang and Schneider 1991). However, the unstructured adenovirus late leader-containing mRNAs (Huang and Schneider 1991) and the IRES elements of poliovirus (Bonneau and Sonenberg 1987) and HCV (Honda et al. 2000) are able to mediate translation initiation efficiently during $G_{2} / M$, suggesting that these mRNAs require little or no phosphorylated eIF4F for ribosome recruitment. Very recently, $\mathrm{G}_{2} / \mathrm{M}$-regulated IRES elements have been identified in the mRNAs encoding ornithine decarboxylase (Pyronnet et al. 2000) and protein kinase p58 $8^{\text {PITSLRE }}$ (Cornelis et al. 2000); in addition, the c-myc IRES was found to be active during $\mathrm{G}_{2} / \mathrm{M}$ (Pyronnet et al. 2000). These experiments showed that inhibition of $5^{\prime}$ end-dependent translation by dephosphorylation of eIF4F correlates with the selective translation of some IRES-containing mRNAs. However, cDNA microarray experiments have shown that several other IRES-containing mRNAs are not selectively translated during $\mathrm{G}_{2} / \mathrm{M}$ (Qin and P. Sarnow, unpubl.), suggesting that other events that take place during $G_{2} / M$ contribute to the translation of selected IRES-containing mRNAs.

\section{IRES-regulated expression of the cationic amino acid transporter cat-1 during amino acid deprivation}

It has been known from studies in $S$. cerevisiae that amino acid deprivation can lead to the phosphorylation of the $\alpha$-subunit of eIF2 (see above), causing the enhanced translation of GCN4 mRNA by a reinitiation mechanism (for review, see Hinnebusch 1997). Recent studies by Hatzoglou and colleagues have shown that amino acid starvation of mammalian cells also results in a rapid phosporylation of eIF $2 \alpha$ (leading to a reduced concentration of ternary complex) and dephosphorylation of eIF4E (leading to a reduced concentration of active eIF4F), events that result in an overall decrease in host cell mRNA translation (Fernandez et al. 2001). The starved cells respond to this stressful situation with the synthesis of proteins involved in amino acid biosynthesis and of amino acid transporters, including the cationic amino acid transporter cat- 1 that mediates the uptake of lysine and arginine (Hyatt et al. 1997). It was unclear how newly transcribed cat- 1 mRNA could be translated when overall translation was inhibited. It was found that by $2 \mathrm{~h}$ after amino acid starvation phosphorylation of eIF2 declined substantially; by $9 \mathrm{~h}$ after starvation, a time when cap-dependent translation was still inhibited, translation of cat-1 mRNA was greatly enhanced (Fernandez et al. 2001). It was found that cat-1 contained an IRES that was significantly enhanced during amino acid deprivation (Fernandez et al. 2001). It will be very interesting to test whether the time lag observed is due to synthetic events: for example, phosphorylation of eIF2 $\alpha$ could promote the synthesis of an ITAF that then would enhance cat-1 IRES-mediated translation. 


\section{IRES-mediated translation during apoptosis}

Table 3 lists IRES-containing cellular mRNAs that are translated during apoptosis, such as c-myc (Stoneley et al. 2000a), apoptotic protease activating factor (Apaf-1; Coldwell et al. 2000) and death-associated protein 5 (DAP5; Henis-Korenblit et al. 2000) mRNAs. It is known that the p38 mitogen-activated protein kinase pathway, which is activated during apoptosis, regulates internal initiation mediated by the c-myc IRES (Stoneley et al. 2000a). Thus, the mechanism and the outcome of the translation of these mRNAs has been under intense scrutiny because it is not immediately clear why proteins that both inhibit (DAP5) and activate (Apaf-1) apoptosis should be synthesized at the onset of programmed cell death.

Insight into this puzzle has come from studies that have examined the fate of the canonical eIFs after the onset of apoptosis. It was found that caspase 3 mediates the proteolysis of eIF2, eIF4B, eIF4GI, eIF4GII, the p35 subunit of eIF3, and eF4E-BP both in vitro and in cells induced to enter apoptosis by a variety of treatments (Clemens et al. 1998; Marissen and Lloyd 1998; Satoh et al. 1999; Bushell et al. 2000b; Marissen et al. 2000a,b). Interestingly, caspase 3-mediated cleavage of eIF4GI in apoptotic lymphoma cells generates a stable, $76-\mathrm{kD} \mathrm{M}$ FAG (middle fragment of apoptotic cleavage of eIF4G) protein that retains the bin $\overline{d i n g}$ sites for eIF4A, eIF3, and eIF4E but loses the binding site for PABP and Mnk1 (Bushell et al. 2000a). The elimination of a role for PABP in translation initiation during apoptosis was supported further by the finding that eIF4B is rapidly cleaved by caspase 3; mammalian eIF4B recently has been found to interact with PABP (Bushell et al. 2001). Overall, these findings suggest that M-FAG could mediate cap-dependent translation, although with less efficiency than eIF4GI, without the aid of PABP in apoptotic cells.

Thus, it was surprising that DAP5/p97 was found to be translated by internal initiation during apoptosis. It is a member of the eIF4G family that inhibits both cap-dependent and IRES-dependent translation (Imataka et al. 1997; Yamanaka et al. 1997) and that lacks the aminoterminal binding sites for PABP and eIF4E. The p97 form of DAP5 was cleaved by caspase 3 near its $\mathrm{C}$ terminus to yield a p86 protein (Henis-Korenblit et al. 2000); interestingly, p86 was found to function as a specific ITAF for the IRES in DAP5/97 (Henis-Korenblit et al. 2000). Therefore, both positive (i.e., M-FAG, DAP/p86) and negative (i.e., DAP5/p97) eIF4G-like molecules and complexes are expected to be present in apoptotic cells. Overall, these findings suggest that the affinity of IRES elements in mRNAs encoding pro- and antiapoptotic proteins for a variety of eIFs and ITAFs might dictate which IRES recruits ribosomal subunits most efficiently at a given time during the onset of apoptosis.

\section{IRES regulation in human disease}

Aberrant IRES-mediated translation can be correlated with the pathogenesis of two human diseases, multiple myeloma and Charcot-Marie-Tooth disease (CMTX). On analysis of several cell lines obtained from patients with multiple myeloma, Willis and colleagues noted that cmyc protein levels were greatly enhanced, without a concomitant increase in the intracellular levels of c-myc mRNA. Inspection of c-myc mRNA revealed a single C to $U$ change in the c-myc IRES in all of the cell lines (Paulin et al. 1996). The mutated c-myc IRES was more active than the wild-type IRES in cell lines derived from patients with multiple myeloma and this activity correlated with the enhanced binding of a distinct set of proteins (Paulin et al. 1998; Chappell et al. 2000b). More recently, the same $\mathrm{C}$ to $\mathrm{U}$ change in the IRES was found in $42 \%$ of bone marrow samples collected from patients with multiple myeloma; this change was not detected in control cells (Chappell et al. 2000b). Thus, there is a correlation between enhanced activity of the c-myc IRES and the development of disease. Whether mutations in other oncogenes have occurred in these cell lines is not yet known.

In a second example, Hudder and Werner showed that down-regulation of nerve-specific connexin 32 mRNA translation correlated with the CMTX phenotype, a neurodegenerative disease (Hudder and Werner 2000). Connexin 32 is a gap junction protein that is expressed by tissue-specific promoters both in the liver and in Schwann cells. Although most mutations in CMTX patients are found in the coding region of connexin 32, Hudder and Werner identified a $\mathrm{C}$ to $\mathrm{U}$ change in the $5^{\prime}$ NTR of connexin 32 that lead to a tremendous inhibition of mRNA translation. Using dicistronic mRNAs and Northern analysis (R. Werner, pers. comm.), it was found that the connexin $5^{\prime}$ NTR contained an IRES element. Using transgenic mice, it was shown that the $\mathrm{C}$ to $\mathrm{U}$ change in the connexin 32 IRES silenced the translation of a mutant IRES-containing reporter mRNA (Hudder and Werner 2000). The reason why connexin 32 mRNA translation is mediated by an IRES not clear. The authors speculated that the synthesis of the small amounts of connexin 32 needed might be fine-tuned to ensure that the gap junction protein is not present at the wrong place in the membrane when large excess of myelin that wraps around the axon is being synthesized (Hudder and Werner 2000).

\section{Summary}

Viral IRES elements with very different structures have revealed that $40 \mathrm{~S}$ ribosomes can be recruited by at least three different mechanisms. As exemplified by the EMCV IRES, interaction of eIF4G/eIF4A with the IRES, aided by canonical eIFs 2,3 , and $4 \mathrm{~B}$, is necessary to recruit $40 \mathrm{~S}$ subunits to the IRES. The HCV IRES can bind eIF-free 40S subunits without helicase eIF4A or other eIFs, yet recruits the ternary complex to position the initiator tRNA into the ribosomal P site. In contrast, the CrPV-like IRES elements can assemble $80 \mathrm{~S}$ ribosomes without any eIF including the initiator tRNA; in fact, parts of the IRES itself occupy the ribosomal $\mathrm{P}$ site. These findings suggest that structural features in IRES 
elements dictate the need for certain eIFs, such as helicase eIF4A, that aid in $40 \mathrm{~S}$ recruitment. Thus, in each of these three mechanisms, ribosomal recruitment involves noncanonical interactions with canonical components of the translation apparatus. Notwithstanding the HAV IRES, even IRESs that require almost all canonical eIFs for 40S recruitment can function without eIF4E. Thus, most IRESs should be refractory to mechanisms that control 5' end-dependent translation via dephosphorylation of eIF4E or sequestration of eIF4E by eIF4Ebinding proteins.

In contrast with viral IRES elements, some cellular IRES elements seem to function in a modular fashion. Certain large IRES elements can be dissected into smaller elements, each of which can display IRES activity. The failure of viral IRES elements to operate in modules may reflect their multifunctional roles in translation, replication, or packaging of the viral genome. Both viral and cellular IRES elements can be regulated by ITAFs in a cell-specific manner, adding complexity to the regulation of IRES elements. Equally important, the continuous activity of certain IRES elements when certain eIFs are limiting, for example, during various situations of cell stress and cell death, points to the biological importance of internal initiation. Translational regulation in the nervous system just recently has become appreciated as playing a crucial role in events such as activity-dependent synaptic changes (Scheetz et al. 2000). The recent finding that certain synaptically located mRNAs contain IRES elements raises the possibility that internal initiation may be used to synthesize proteins that are involved in regulation of synaptic plasticity (Scheetz et al. 2000; Pinkstaff et al. 2001).

\section{Acknowledgments}

We apologize to investigators whose work has not been discussed in detail due to space limitations. We are grateful to Karla Kirkegaard and Martin Bushell for critical reading of the manuscript. We thank Richard J. Jackson for valuable suggestions. We are also indebted to Jennifer Doudna, Joachim Frank, Nobuhiko Nakashima, Anne-Catherine Prats, Rene Rijnbrand, and Anne Willis for communication of results prior to publication. Work performed in the authors' laboratories were supported by grants from the NIH (C.U.T.H., P.S., and T.V. Pestova), from the NSF (C.U.T.H.), and from the Hutchison Foundation and Eli Lilly, Inc. (P.S.).

\section{References}

Akiri, G., Nahari, D., Finkelstein, Y., Le, S.Y., Elroy-Stein, O. and Levi., B.Z. 1998. Regulation of vascular endothelial growth factor (VEGF) expression is mediated by internal initiation of translation and alternative initiation of transcription. Oncogene 17: 227-236.

Ali, N. and Siddiqui, A. 1995. Interaction of polypyrimidine tract-binding protein with the 5 ' noncoding region of the hepatitis $\mathrm{C}$ virus RNA genome and its functional requirement in internal initiation of translation. J. Virol. 69: 63676375.

1997. The La antigen binds $5^{\prime}$ noncoding region of the hepatitis $\mathrm{C}$ virus RNA in the context of the initiator AUG codon and stimulates internal ribosome entry site-mediated translation. Proc. Natl. Acad. Sci. 94: 2249-2254.

Anwar, A., Ali, N., Tanveer, R., and Siddiqui, A. 2000. Demonstration of functional requirement of polypyrimidine tractbinding protein by SELEX RNA during hepatitis C virus internal ribosome entry site-mediated translation initiation. $J$. Biol. Chem. 275: 34231-34235.

Arrick, B.A., Lee, A.L., Grendell, R.L., and Derynck, R. 1991. Inhibition of translation of transforming growth factor- $\beta 3$ mRNA by its $5^{\prime}$ untranslated region. Mol. Cell. Biol. 11: 4306-4313.

Belsham, G.J. 1992. Dual initiation sites of protein synthesis on foot-and-mouth disease virus RNA are selected following internal entry and scanning of ribosomes in vivo. EMBO $J$. 11: 1105-1110.

Beretta, L., Gingras, A.C., Svitkin, Y.V., Hall, M.N., and Sonenberg, N. 1996. Rapamycin blocks the phosphorylation of 4EBP1 and inhibits cap-dependent initiation of translation. EMBO T. 15: 658-664.

Bergamini, G., Preiss, T., and Hentze, M.W. 2000. Picornavirus IRESes and the poly(A) tail jointly promote cap-independent translation in a mammalian cell-free system. RNA 6: 17811790.

Berlioz, C. and Darlix, J.L. 1995. An internal ribosomal entry mechanism promotes translation of murine leukemia virus gag polyprotein precursors. J. Virol. 69: 2214-2222.

Bernstein, J., Sella, O., Le, S.Y., and Elroy-Stein, O. 1997. PDGF2/c-sis mRNA leader contains a differentiation-linked internal ribosomal entry site (D-IRES). I. Biol. Chem. 272: 9356-9362.

Bieleski, L. and Talbot, S.J. 2001. Kaposi's sarcoma-associated herpesvirus vCyclin open reading frame contains an internal ribosome entry site. J. Virol. 75: 1864-1869.

Blyn, L.B., Swiderek, K.M., Richards, O., Stahl, D.C., Semler, B.L., and Ehrenfeld, E. 1996. Poly(rC) binding protein 2 binds to stem-loop IV of the poliovirus RNA $5^{\prime}$ noncoding region: Identification by automated liquid chromatography-tandem mass spectrometry. Proc. Natl. Acad. Sci. 93: 11115-11120.

Blyn, L.B., Towner, J.S., Semler, B.L., and Ehrenfeld, E. 1997. Requirement of poly $(\mathrm{rC})$ binding protein 2 for translation of poliovirus RNA. J. Virol. 71: 6243-6246.

Bonneau, A.M. and Sonenberg, N. 1987. Involvement of the $24-\mathrm{kDa}$ cap-binding protein in regulation of protein synthesis in mitosis. J. Biol. Chem. 262: 11134-11139.

Borman, A. and Jackson, R.J. 1992. Initiation of translation of human rhinovirus RNA: Mapping the internal ribosome entry site. Virology 188: 685-696.

Borman, A.M. and Kean, K.M. 1997. Intact eukaryotic initiation factor $4 \mathrm{G}$ is required for hepatitis A virus internal initiation of translation. Virology 237: 129-136.

Borman, A.M., Bailly, J.L., Girard, M., and Kean, K.M. 1995. Picornavirus internal ribosome entry segments: Comparison of translation efficiency and the requirements for optimal internal initiation of translation in vitro. Nucleic Acids Res. 23: 3656-3663.

Brown, B.A. and Ehrenfeld, E. 1979. Translation of poliovirus RNA in vitro: Changes in cleavage pattern and initiation sites by ribosomal salt wash. Virology 97: 396-405.

Buratti, E., Tisminetzky, S., Zotti, M., and Baralle, F.E. 1998. Functional analysis of the interaction between HCV 5' UTR and putative subunits of eukaryotic translation initiation factor eIF3. Nucleic Acids Res. 26: 3179-3187.

Bushell, M., Poncet, D., Marissen, W.E., Flotow, H., Lloyd, R.E., Clemens, M.J., and Morley, S.J. 2000a. Cleavage of polypeptide chain initiation factor eIF4GI during apoptosis in lym- 
phoma cells: Characterisation of an internal fragment generated by caspase-3-mediated cleavage. Cell Death Differ. 7: 628-636.

Bushell, M., Wood, W., Clemens, M.J., and Morley, S.J. 2000b. Changes in integrity and association of eukaryotic protein synthesis initiation factors during apoptosis. Eur. I. Biochem. 267: 1083-1091.

Bushell, M., Wood, W., Carpenter, G., Pain, V.M., Morley, S.J., and Clemens, M.J. 2001. Disruption of the interaction of mammalian protein synthesis initiation factor $4 \mathrm{~B}$ with the poly(A) binding protein by caspase- and viral protease-mediated cleavages. J. Biol. Chem. (in press).

Canaani, D., Revel, M., and Groner, Y. 1976. Translational discrimination of "capped" and "non-capped" mRNAS: Inhibition of a series of chemical analogs of m7GpppX. FEBS Lett. 64: 326-331.

Chappell, S.A., Edelman, G.M., and Mauro, V.P. 2000a. A 9-nt segment of a cellular mRNA can function as an internal ribosome entry site (IRES) and when present in linked multiple copies greatly enhances IRES activity. Proc. Natl. Acad. Sci. 97: 1536-1541.

Chappell, S.A., LeQuesne, J.P., Paulin, F.E., deSchoolmeester, M.L., Stoneley, M., Soutar, R.L., Ralston, S.H., Helfrich, M.H., and Willis, A.E. 2000b. A mutation in the c-myc-IRES leads to enhanced internal ribosome entry in multiple myeloma: A novel mechanism of oncogene de-regulation. Oncogene 19: 4437-4440.

Chen, C.Y. and Sarnow, P. 1995. Initiation of protein synthesis by the eukaryotic translational apparatus on circular RNAs. Science 268: 415-417.

Clemens, M.J., Bushell, M., and Morley, S.J. 1998. Degradation of eukaryotic polypeptide chain initiation factor (eIF) 4G in response to induction of apoptosis in human lymphoma cell lines. Oncogene 17: 2921-2931.

Coldwell, M.J., Mitchell, S.A., Stoneley, M., MacFarlane, M., and Willis, A.E. 2000. Initiation of Apaf-1 translation by internal ribosome entry. Oncogene 19: 899-905.

Cornelis, S., Bruynooghe, Y., Denecker, G., Van Huffel, S., Tinton, S., and Beyaert, R. 2000. Identification and characterization of a novel cell cycle-regulated internal ribosome entry site. Mol. Cell 5: 597-605.

Correll, C.C., Munishkin, A., Chan, Y.L., Ren, Z., Wool, I.G., and Steitz, T.A. 1998. Crystal structure of the ribosomal RNA domain essential for binding elongation factors. Proc. Natl. Acad. Sci. 95: 13436-13441.

Creancier, L., Morello, D., Mercier, P., and Prats, A.C. 2000. Fibroblast growth factor 2 internal ribosome entry site (IRES) activity ex vivo and in transgenic mice reveals a stringent tissue-specific regulation. J. Cell Biol. 150: 275-281.

Deffaud, C. and Darlix, J.L. 2000. Rous sarcoma virus translation revisited: Characterization of an internal ribosome entry segment in the $5^{\prime}$ leader of the genomic RNA. J. Virol. 74: 11581-11588.

Dolph, P.J., Racaniello, V.R., Villamarin, A., Palladino, F., and Schneider, R.J. 1988. The adenovirus tripartite leader eliminates the requirement for cap binding protein during translation initiation. J. Virol. 62: 2059-2066.

Domier, L.L., McCoppin, N.K., and D'Arcy, C.J. 2000. Sequence requirements for translation initiation of Rhopalosiphum padi virus ORF2. Virology 268: 264-271.

Donahue, T.F. 2000. Genetic approaches to translation initiation in Saccharomyces cerevisiae. In Translational control of gene expression (eds. N. Sonenberg, et al.), pp. 487-502. Cold Spring Harbor Laboratory Press, Cold Spring Harbor, NY.

Fernandez, J., Yaman, I., Mishra, R., Merrick, W.C., Snider,
M.D., Lamers, W.H., and Hatzoglou, M. 2001. Internal ribosome entry site-mediated translation of a mammalian mRNA is regulated by amino acid availability. J. Biol. Chem. 276: 12285-12291.

Futterer, J., Kiss-Laszlo, Z., and Hohn, T. 1993. Nonlinear ribosome migration on cauliflower mosaic virus 35 S RNA. Cell 73: 789-802.

Gamarnik, A.V. and Andino, R. 1997. Two functional complexes formed by $\mathrm{KH}$ domain containing proteins with the $5^{\prime}$ noncoding region of poliovirus RNA. RNA 3: 882-892.

- 2000. Interactions of viral protein $3 \mathrm{CD}$ and Poly $(\mathrm{rC})$ binding protein with the $5^{\prime}$ untranslated region of the poliovirus genome. J. Virol. 74: 2219-2226.

Gan, W. and Rhoads, R.E. 1996. Internal initiation of translation directed by the $5^{\prime}$-untranslated region of the mRNA for eIF4G, a factor involved in the picornavirus-induced switch from cap-dependent to internal initiation. J. Biol. Chem. 271: 623-626.

Ghetti, A., Pinol-Roma, S., Michael, W.M., Morandi, C., and Dreyfuss, G. 1992. hnRNP I, the polypyrimidine tract-binding protein: Distinct nuclear localization and association with hnRNAs. Nucleic Acids Res. 20: 3671-3678.

Gingras, A.C., Svitkin, Y., Belsham, G.J., Pause, A., and Sonenberg, N. 1996. Activation of the translational suppressor 4EBP1 following infection with encephalomyocarditis virus and poliovirus. Proc. Natl. Acad. Sci. 93: 5578-5583.

Gingras, A.C., Raught, B., and Sonenberg, N. 1999. eIF4 initiation factors: Effectors of mRNA recruitment to ribosomes and regulators of translation. Annu. Rev. Biochem. 68: 913963.

Gosert, R., Chang, K.H., Rijnbrand, R., Yi, M., Sangar, D.V., and Lemon, S.M. 2000. Transient expression of cellular polypyrimidine-tract binding protein stimulates cap-independent translation directed by both picornaviral and flaviviral internal ribosome entry sites in vivo. Mol. Cell. Biol. 20: 15831595.

Grace, K., Gartland, M., Karayiannis, P., McGarvey, M.J., and Clarke, B. 1999. The 5' untranslated region of GB virus B shows functional similarity to the internal ribosome entry site of hepatitis C virus. J. Gen. Virol. 80: 2337-2341.

Gradi, A., Svitkin, Y.V., Imataka, H., and Sonenberg, N. 1998. Proteolysis of human eukaryotic translation initiation factor eIF4GII, but not eIF4GI, coincides with the shutoff of host protein synthesis after poliovirus infection. Proc. Natl. Acad. Sci. 95: 11089-11094.

Grundhoff, A. and Ganem, D. 2001. Mechanisms governing expression of the v-FLIP gene of Kaposi's sarcoma-associated herpesvirus. J. Virol. 75: 1857-1863.

Gustin, K.E. and Sarnow, P. 2001. Effects of poliovirus infection on nucleo-cytoplasmic trafficking and nuclear pore composition. EMBO J. 20: 240-249.

Hahm, B., Kim, Y.K., Kim, J.H., Kim, T.Y., and Jang, S.K. 1998. Heterogeneous nuclear ribonucleoprotein $\mathrm{L}$ interacts with the $3^{\prime}$ border of the internal ribosomal entry site of hepatitis C virus. J. Virol. 72: 8782-8788.

Hambidge, S.J. and Sarnow, P. 1992. Translational enhancement of the poliovirus $5^{\prime}$ noncoding region mediated by virus-encoded polypeptide 2A. Proc. Natl. Acad. Sci. 89: 10272-10276.

Hayashi, S., Nishimura, K., Fukuchi-Shimogori, T., Kashiwagi, K., and Igarashi, K. 2000. Increase in cap- and IRES-dependent protein synthesis by overproduction of translation initiation factor eIF4G. Biochem. Biophys. Res. Commun. 277: 117-123.

Hellen, C.U., Pestova, T.V., and Wimmer, E. 1994. Effect of mutations downstream of the internal ribosome entry site 
on initiation of poliovirus protein synthesis. I. Virol. 68: 6312-6322.

Henis-Korenblit, S., Strumpf, N.L., Goldstaub, D., and Kimchi, A. 2000. A novel form of DAP5 protein accumulates in apoptotic cells as a result of caspase cleavage and internal ribosome entry site-mediated translation. Mol. Cell. Biol. 20: 496-506.

Hentze, M.W. 1997. eIF4G: A multipurpose ribosome adapter? Science 275: 500-501.

Hershey, J.W.B. and Merrick, W.C. 2000. The pathway and mechanism of initiation of protein synthesis. In Translational control of gene expression (ed. N. Sonenberg, et al.), pp. 33-88. Cold Spring Harbor Laboratory Press, Cold Spring Harbor, NY.

Hinnebusch, A.G. 1997. Translational regulation of yeast GCN4. A window on factors that control initiator-trna binding to the ribosome. J. Biol. Chem. 272: 21661-21664.

Holcik, M. and Korneluk, R.G. 2000. Functional characterization of the X-linked inhibitor of apoptosis (XIAP) internal ribosome entry site element: Role of La autoantigen in XIAP translation. Mol. Cell. Biol. 20: 4648-4657.

Holcik, M., Sonenberg, N., and Korneluk, R.G. 2000. Internal ribosome initiation of translation and the control of cell death. Trends Genet. 16: 469-473.

Honda, M., Ping, L.H., Rijnbrand, R.C., Amphlett, E., Clarke, B., Rowlands, D., and Lemon, S.M. 1996. Structural requirements for initiation of translation by internal ribosome entry within genome-length hepatitis C virus RNA. Virology 222: $31-42$.

Honda, M., Beard, M.R., Ping, L.H., and Lemon, S.M. 1999. A phylogenetically conserved stem-loop structure at the $5^{\prime}$ border of the internal ribosome entry site of hepatitis $\mathrm{C}$ virus is required for cap-independent viral translation. J. Virol. 73: $1165-1174$.

Honda, M., Kaneko, S., Matsushita, E., Kobayashi, K., Abell, G.A., and Lemon, S.M. 2000. Cell cycle regulation of hepatitis $\mathrm{C}$ virus internal ribosomal entry site-directed translation. Gastroenterology 118: 152-162.

Hu, M.C., Tranque, P., Edelman, G.M., and Mauro, V.P. 1999. rRNA-complementarity in the $5^{\prime}$ untranslated region of mRNA specifying the Gtx homeodomain protein: Evidence that base- pairing to $18 \mathrm{~S}$ rRNA affects translational efficiency. Proc. Nat1. Acad. Sci. 96: 1339-1344.

Huang, J.T. and Schneider, R.J. 1991. Adenovirus inhibition of cellular protein synthesis involves inactivation of cap-binding protein. Cell 65: 271-280.

Hudder, A. and Werner, R. 2000. Analysis of a charcot-marietooth disease mutation reveals an essential internal ribosome entry site element in the connexin-32 gene. J. Biol. Chem. 275: 34586-34591.

Huez, I., Creancier, L., Audigier, S., Gensac, M.C., Prats, A.C., and Prats, H. 1998. Two independent internal ribosome entry sites are involved in translation initiation of vascular endothelial growth factor mRNA. Mol. Cell. Biol. 18: 61786190.

Hunt, S.L., Hsuan, J.J., Totty, N., and Jackson, R.J. 1999. unr, a cellular cytoplasmic RNA-binding protein with five coldshock domains, is required for internal initiation of translation of human rhinovirus RNA. Genes \& Dev. 13: 437-448.

Hyatt, S.L., Aulak, K.S., Malandro, M., Kilberg, M.S., and Hatzoglou, M. 1997. Adaptive regulation of the cationic amino acid transporter-1 (Cat-1) in Fao cells. I. Biol. Chem. 272: 19951-19957.

Imataka, H., Olsen, H.S., and Sonenberg, N. 1997. A new translational regulator with homology to eukaryotic translation initiation factor 4G. EMBO J. 16: 817-825.
Izquierdo, J.M. and Cuezva, J.M. 2000. Internal-ribosome-entrysite functional activity of the 3 '-untranslated region of the mRNA for the beta subunit of mitochondrial H+-ATP synthase. Biochem. J. 346: 849-855.

Jackson, R.J. and Kaminski, A. 1995. Internal initiation of translation in eukaryotes: The picornavirus paradigm and beyond. RNA 1: 985-1000.

Jang, S.K., Krausslich, H.G., Nicklin, M.J., Duke, G.M., Palmenberg, A.C., and Wimmer, E. 1988. A segment of the 5' nontranslated region of encephalomyocarditis virus RNA directs internal entry of ribosomes during in vitro translation. $J$. Virol. 62: 2636-2643.

Johannes, G. and Sarnow, P. 1998. Cap-independent polysomal association of natural mRNAs encoding c-myc, BiP, and eIF4G conferred by internal ribosome entry sites. RNA 4: 1500-1513.

Johannes, G., Carter, M.S., Eisen, M.B., Brown, P.O., and Sarnow, P. 1999. Identification of eukaryotic mRNAs that are translated at reduced cap binding complex eIF4F concentrations using a cDNA microarray. Proc. Natl. Acad. Sci. 96: $13118-13123$.

Jubin, R., Vantuno, N.E., Kieft, J.S., Murray, M.G., Doudna, J.A., Lau, J.Y., and Baroudy, B.M. 2000. Hepatitis C virus internal ribosome entry site (IRES) stem loop IIId contains a phylogenetically conserved GGG triplet essential for translation and IRES folding. J. Virol. 74: 10430-10437.

Kaminski, A. and Jackson, R.J. 1998. The polypyrimidine tract binding protein $(\mathrm{PTB})$ requirement for internal initiation of translation of cardiovirus RNAs is conditional rather than absolute. RNA 4: 626-638.

Kaminski, A., Howell, M.T., and Jackson, R.J. 1990. Initiation of encephalomyocarditis virus RNA translation: The authentic initiation site is not selected by a scanning mechanism. EMBO I. 9: 3753-3759.

Kaminski, A., Belsham, G.J., and Jackson, R.J. 1994. Translation of encephalomyocarditis virus RNA: Parameters influencing the selection of the internal initiation site. $E M B O J$. 13: $1673-1681$.

Kaminski, A., Hunt, S.L., Patton, J.G., and Jackson, R.J. 1995. Direct evidence that polypyrimidine tract binding protein $(\mathrm{PTB})$ is essential for internal initiation of translation of encephalomyocarditis virus RNA. RNA 1: 924-938.

Kanamori, Y. and Nakashima, N. 2001. A tertiary structure model of the internal ribosome entry site (IRES) for methionine-independent initiation of translation. RNA 7: 266-274.

Kaufman, R.J. 1999. Stress signaling from the lumen of the endoplasmic reticulum: Coordination of gene transcriptional and translational controls. Genes \& Dev. 13: 1211-1233.

Kieft, J.S., Zhou, K., Jubin, R., Murray, M.G., Lau, J.Y., and Doudna, J.A. 1999. The hepatitis C virus internal ribosome entry site adopts an ion-dependent tertiary fold. J. Mol. Biol. 292: 513-529.

Kieft, J.S., Zhou, K., Jubin, R., and Doudna, J.A. 2001. Mechanism of ribosome recruitment by hepatitis C IRES RNA. RNA 7: 194-206.

Kim, J.G., Armstrong, R.C., Berndt, J.A., Kim, N.W., and Hudson, L.D. 1998. A secreted DNA-binding protein that is translated through an internal ribosome entry site (IRES) and distributed in a discrete pattern in the central nervous system. Mol. Cell Neurosci. 12: 119-140.

Kim, Y.K., Hahm, B., and Jang, S.K. 2000. Polypyrimidine tractbinding protein inhibits translation of bip mRNA. I. Mol. Biol. 304: 119-133.

Klinck, R., Westhof, E., Walker, S., Afshar, M., Collier, A., and Aboul-Ela, F. 2000. A potential RNA drug target in the hepa- 
titis C virus internal ribosomal entry site. RNA 6: 14231431.

Kolupaeva, V.G., Hellen, C.U., and Shatsky, I.N. 1996. Structural analysis of the interaction of the pyrimidine tract-binding protein with the internal ribosomal entry site of encephalomyocarditis virus and foot-and-mouth disease virus RNAs. RNA 2: 1199-1212.

Kolupaeva, V.G., Pestova, T.V., Hellen, C.U., and Shatsky, I.N. 1998. Translation eukaryotic initiation factor $4 \mathrm{G}$ recognizes a specific structural element within the internal ribosome entry site of encephalomyocarditis virus RNA. I. Biol. Chem. 273: 18599-18604.

Kolupaeva, V.G., Pestova, T.V., and Hellen, C.U. 2000a. An enzymatic footprinting analysis of the interaction of $40 \mathrm{~S}$ ribosomal subunits with the internal ribosomal entry site of hepatitis C virus. J. Virol. 74: 6242-6250.

- 2000b. Ribosomal binding to the internal ribosomal entry site of classical swine fever virus. RNA 6: 1791-1807.

Konarska, M., Filipowicz, W., Domdey, H., and Gross, H.J. 1981. Binding of ribosomes to linear and circular forms of the $5^{\prime}$ terminal leader fragment of tobacco-mosaic-virus RNA. Eur. J. Biochem. 114: 221-227.

Kozak, M. 1979. Inability of circular mRNA to attach to eukaryotic ribosomes. Nature 280: 82-85.

-1987. At least six nucleotides preceding the AUG initiator codon enhance translation in mammalian cells. J. Mol. Biol. 196: 947-950.

1989. The scannning model for translation: An update. J. Cell Biol. 108: 229-241.

- 1991. Structural features in eukaryotic mRNAs that modulate the initiation of translation. I. Biol. Chem. 266: $19867-19870$.

Kuge, S. and Nomoto, A. 1987. Construction of viable deletion and insertion mutants of the Sabin strain of type 1 poliovirus: Function of the $5^{\prime}$ noncoding sequence in viral replication. J. Virol. 61: 1478-1487.

Lamphear, B.J., Yan, R., Yang, F., Waters, D., Liebig, H.D., Klump, H., Kuechler, E., Skern, T., and Rhoads, R.E. 1993. Mapping the cleavage site in protein synthesis initiation factor eIF-4 gamma of the 2A proteases from human Coxsackievirus and rhinovirus. J. Biol. Chem. 268: 19200-19203.

Lamphear, B.J., Kirchweger, R., Skern, T., and Rhoads, R.E. 1995. Mapping of functional domains in eukaryotic protein synthesis initiation factor 4G (eIF4G) with picornaviral proteases. Implications for cap-dependent and cap-independent translational initiation. J. Biol. Chem. 270: 21975-21983.

Lauring, S.A. and Overbaugh, J. 2000. Evidence that an IRES within the Notch 2 coding region can direct expression of a nuclear form of the protein. Mol. Cell. 6: 939-945.

Le, S.Y. and Maizel, Jr., J.V. 1997. A common RNA structural motif involved in the internal initiation of translation of cellular mRNAs. Nucleic Acids Res. 25: 362-369.

Lemon, S.M. and Honda, M. 1997. Internal ribosome entry sites within the RNA genomes of hepatitis $\mathrm{C}$ virus and other flaviviruses. Semin. Virol. 8: 274-288.

Lomakin, I.B., Hellen, C.U., and Pestova, T.V. 2000. Physical association of eukaryotic initiation factor 4G (eIF4G) with eIF4A strongly enhances binding of eIF4G to the internal ribosomal entry site of encephalomyocarditis virus and is required for internal initiation of translation. Mol. Cell. Biol. 20: 6019-6029.

Lu, H.H. and Wimmer, E. 1996. Poliovirus chimeras replicating under the translational control of genetic elements of hepatitis $\mathrm{C}$ virus reveal unusual properties of the internal ribosomal entry site of hepatitis C virus. Proc. Natl. Acad. Sci. 93: $1412-1417$.
Lukavsky, P.J., Otto, G.A., Lancaster, A.M., Sarnow, P., and Puglisi, J.D. 2000. Structures of two RNA domains essential for hepatitis $\mathrm{C}$ virus internal ribosome entry site function. Nat. Struct. Biol. 7: 1105-1110.

Macejak, D.G. and Sarnow, P. 1991. Internal initiation of translation mediated by the $5^{\prime}$ leader of a cellular mRNA. Nature 353: 90-94.

Marcotrigiano, J., Lomakin, I.B., Sonenberg, N., Pestova, T.V., Hellen, C.U.T., and Burley, S.K. 2001. A conserved HEAT domain within eIF4G directs assembly of the translation initiation machinery. Mol. Cell 7: 193-203.

Marissen, W.E. and Lloyd, R.E. 1998. Eukaryotic translation initiation factor $4 \mathrm{G}$ is targeted for proteolytic cleavage by caspase 3 during inhibition of translation in apoptotic cells. Mol. Cell. Biol. 18: 7565-7574.

Marissen, W.E., Gradi, A., Sonenberg, N., and Lloyd, R.E. 2000a. Cleavage of eukaryotic translation initiation factor 4GII correlates with translation inhibition during apoptosis. Cell Death Differ. 7: 1234-1243.

Marissen, W.E., Guo, Y., Thomas, A.A., Matts, R.L., and Lloyd, R.E. 2000b. Identification of caspase 3-mediated cleavage and functional alteration of eukaryotic initiation factor $2 \alpha$ in apoptosis. J. Biol. Chem. 275: 9314-9323.

Marth, J.D., Overell, R.W., Meier, K.E., Krebs, E.G., and Perlmutter, R.M. 1988. Translational activation of the lck proto-oncogene. Nature 332: 171-173.

Mauro, V.P. and Edelman, G.M. 1997. rRNA-like sequences occur in diverse primary transcripts: Implications for the control of gene expression. Proc. Natl. Acad. Sci. 94: 422-427.

Meerovitch, K., Svitkin, Y.V., Lee, H.S., Lejbkowicz, F., Kenan, D.J., Chan, E.K., Agol, V.I., Keene, J.D., and Sonenberg, N. 1993. La autoantigen enhances and corrects aberrant translation of poliovirus RNA in reticulocyte lysate. J. Virol. 67: 3798-3807.

Meyer, K., Petersen, A., Niepmann, M., and Beck, E. 1995. Interaction of eukaryotic initiation factor eIF-4B with a picornavirus internal translation initiation site. J. Virol. 69: 28192824.

Michel, Y.M., Poncet, D., Piron, M., Kean, K.M., and Borman, A.M. 2000. Cap-Poly(A) synergy in mammalian cell-free extracts. Investigation of the requirements for poly(A)-mediated stimulation of translation initiation. J. Biol. Chem. 275: 32268-32276.

Mitchell, S.A., Brown, E.C., Coldwell, M.J., Jackson, R.J., and Willis, A.E. 2001. Protein factor requirements of the Apaf-1 internal ribosome entry segment: Roles of polypyrimidine tract binding protein and upstream of N-ras. Mol. Cell. Biol. 21: 3364-3374.

Morris, D.R. and Geballe, A.P. 2000. Upstream open reading frames as regulators of mRNA translation. Mol. Cell. Biol. 20: $8635-8642$.

Myers, T.M., Kolupaeva, V.G., Mendez, E., Baginski, S., Frolov, I., Hellen, C.U.T., and Rice, C.M. 2001. Efficient translation initiation is required for replication of bovine viral diarrhea virus subgenomic replicons. J. Virol. 75: 4226-4238.

Nanbru, C., Lafon, I., Audigier, S., Gensac, M.C., Vagner, S., Huez, G., and Prats, A.C. 1997. Alternative translation of the proto-oncogene c-myc by an internal ribosome entry site. $J$. Biol. Chem. 272: 32061-32066.

Nomoto, A., Kitamura, N., Golini, F., and Wimmer, E. 1977. The 5 '-terminal structures of poliovirion RNA and poliovirus mRNA differ only in the genome-linked protein VPg. Proc. Natl. Acad. Sci. 74: 5345-5349.

Odreman-Macchioli, F.E., Tisminetzky, S.G., Zotti, M., Baralle, F.E., and Buratti, E. 2000. Influence of correct secondary and tertiary RNA folding on the binding of cellular factors to the 
HCV IRES. Nucleic Acids Res. 28: 875-885.

Oh, S.K., Scott, M.P., and Sarnow, P. 1992. Homeotic gene Antennapedia mRNA contains $5^{\prime}$-noncoding sequences that confer translational initiation by internal ribosome binding. Genes \& Dev. 6: 1643-1653.

Ohlmann, T. and Jackson, R.J. 1999. The properties of chimeric picornavirus IRESes show that discrimination between internal translation initiation sites is influenced by the identity of the IRES and not just the context of the AUG codon. RNA 5: 764-778.

Oumard, A., Hennecke, M., Hauser, H., and Nourbakhsh, M. 2000. Translation of NRF mRNA is mediated by highly efficient internal ribosome entry. Mol. Cell. Biol. 20: 27552759.

Paulin, F.E., West, M.J., Sullivan, N.F., Whitney, R.L., Lyne, L., and Willis, A.E. 1996. Aberrant translational control of the c-myc gene in multiple myeloma. Oncogene 13: 505-513.

Paulin, F.E., Chappell, S.A., and Willis, A.E. 1998. A single nucleotide change in the c-myc internal ribosome entry segment leads to enhanced binding of a group of protein factors. Nucleic Acids Res. 26: 3097-3103.

Pause, A., Belsham, G.J., Gingras, A.C., Donze, O., Lin, T.A., Lawrence, J.C., and Sonenberg, N. 1994a. Insulin-dependent stimulation of protein synthesis by phosphorylation of a regulator of 5'-cap function. Nature 371: 762-767.

Pause, A., Methot, N., Svitkin, Y., Merrick, W.C., and Sonenberg, N. 1994b. Dominant negative mutants of mammalian translation initiation factor eIF-4A define a critical role for eIF-4F in cap-dependent and cap-independent initiation of translation. EMBO J. 13: 1205-1215.

Pelletier, J. and Sonenberg, N. 1988. Internal initiation of translation of eukaryotic mRNA directed by a sequence derived from poliovirus RNA. Nature 334: 320-325.

Pelletier, J., Flynn, M.E., Kaplan, G., Racaniello, V., and Sonenberg, N. 1988. Mutational analysis of upstream AUG codons of poliovirus RNA. J. Virol. 62: 4486-4492.

Pestova, T.V. and Hellen, C.U. 1999. Internal initiation of translation of bovine viral diarrhea virus RNA. Virology 258: 249256.

Pestova, T.V., Hellen, C.U., and Wimmer, E. 1994. A conserved AUG triplet in the $5^{\prime}$ nontranslated region of poliovirus can function as an initiation codon in vitro and in vivo. Virology 204: 729-737.

Pestova, T.V., Hellen, C.U., and Shatsky, I.N. 1996a. Canonical eukaryotic initiation factors determine initiation of translation by internal ribosomal entry. Mol. Cell. Biol. 16: 68596869.

Pestova, T.V., Shatsky, I.N., and Hellen, C.U. 1996b. Functional dissection of eukaryotic initiation factor 4F: The 4A subunit and the central domain of the 4G subunit are sufficient to mediate internal entry of $43 \mathrm{~S}$ preinitiation complexes. Mol. Cell. Biol. 16: 6870-6878.

Pestova, T.V., Borukhov, S.I., and Hellen, C.U. 1998a. Eukaryotic ribosomes require initiation factors 1 and $1 \mathrm{~A}$ to locate initiation codons. Nature 394: 854-859.

Pestova, T.V., Shatsky, I.N., Fletcher, S.P., Jackson, R.J., and Hellen, C.U. 1998b. A prokaryotic-like mode of cytoplasmic eukaryotic ribosome binding to the initiation codon during internal translation initiation of hepatitis $\mathrm{C}$ and classical swine fever virus RNAs. Genes \& Dev. 12: 67-83.

Pestova, T.V., Lomakin, I.B., Lee, J.H., Choi, S.K., Dever, T.E., and Hellen, C.U. 2000. The joining of ribosomal subunits in eukaryotes requires eIF5B. Nature 403: 332-335.

Pilipenko, E.V., Blinov, V.M., Chernov, B.K., Dmitrieva, T.M., and Agol, V.I. 1989a. Conservation of the secondary structure elements of the $5^{\prime}$-untranslated region of cardio- and aphthovirus RNAs. Nucleic Acids Res. 17: 5701-5711.

Pilipenko, E.V., Blinov, V.M., Romanova, L.I., Sinyakov, A.N., Maslova, S.V., and Agol, V.I. 1989b. Conserved structural domains in the $5^{\prime}$-untranslated region of picornaviral genomes: An analysis of the segment controlling translation and neurovirulence. Virology 168: 201-209.

Pilipenko, E.V., Gmyl, A.P., Maslova, S.V., Belov, G.A., Sinyakov, A.N., Huang, M., Brown, T.D., and Agol, V.I. 1994. Starting window, a distinct element in the cap-independent internal initiation of translation on picornaviral RNA. I. Mol. Biol. 241: 398-414.

Pilipenko, E.V., Pestova, T.V., Kolupaeva, V.G., Khitrina, E.V., Poperechnaya, A.N., Agol, V.I., and Hellen, C.U. 2000. A cell cycle-dependent protein serves as a template-specific translation initiation factor. Genes \& Dev. 14: 2028-2045.

Pinkstaff, J.K., Chappell, S.A., Mauro, V.P., Edelman, G.M., and Krushel, L.A. 2001. Internal initiation of translation of five dendritically localized neuronal mRNAs. Proc. Natl. Acad. Sci. 98: 2770-2775.

Poole, T.L., Wang, C., Popp, R.A., Potgieter, L.N., Siddiqui, A., and Collett, M.S. 1995. Pestivirus translation initiation occurs by internal ribosome entry. Virology 206: 750-754.

Pozner, A., Goldenberg, D., Negreanu, V., Le, S.Y., Elroy-Stein, O., Levanon, D., and Groner, Y. 2000. Transcription-coupled translation control of AML1/RUNX1 is mediated by capand internal ribosome entry site-dependent mechanisms. Mol. Cell. Biol. 20: 2297-2307.

Pyronnet, S., Pradayrol, L., and Sonenberg, N. 2000. A cell cycledependent internal ribosome entry site. Mol. Cell. 5: 607616.

Reynolds, J.E., Kaminski, A., Kettinen, H.J., Grace, K., Clarke, B.E., Carroll, A.R., Rowlands, D.J., and Jackson, R.J. 1995. Unique features of internal initiation of hepatitis $\mathrm{C}$ virus RNA translation. EMBO J. 14: 6010-6020.

Reynolds, J.E., Kaminski, A., Carroll, A.R., Clarke, B.E., Rowlands, D.J., and Jackson, R.J. 1996. Internal initiation of translation of hepatitis $\mathrm{C}$ virus RNA: The ribosome entry site is at the authentic initiation codon. RNA 2: 867-878.

Rijnbrand, R., van der Straaten, T., van Rijn, P.A., Spaan, W.J., and Bredenbeek, P.J. 1997. Internal entry of ribosomes is directed by the $5^{\prime}$ noncoding region of classical swine fever virus and is dependent on the presence of an RNA pseudoknot upstream of the initiation codon. J. Virol. 71: 451-457.

Rijnbrand, R., Abell, G., and Lemon, S.M. 2000. Mutational analysis of the GB virus B internal ribosome entry site. J. Virol. 74: 773-783.

Sachs, A.B. and Varani, G. 2000. Eukaryotic translation initiation: There are (at least) two sides to every story. Nat. Struct. Biol. 7: 356-361.

Sangar, D.V., Newton, S.E., Rowlands, D.J., and Clarke, B.E. 1987. All foot and mouth disease virus serotypes initiate protein synthesis at two separate AUGs. Nucleic Acids Res. 15: 3305-3315.

Sarnow, P. 1989. Translation of glucose-regulated protein 78/ immunoglobulin heavy-chain binding protein mRNA is increased in poliovirus-infected cells at a time when cap-dependent translation of cellular mRNA is inhibited. Proc. Natl. Acad. Sci. 86: 5795-5799.

Sasaki, J. and Nakashima, N. 1999. Translation initiation at the CUU codon is mediated by the internal ribosome entry site of an insect picorna-like virus in vitro. J. Virol. 73: 12191226.

- 2000. Methionine-independent initiation of translation in the capsid protein of an insect RNA virus. Proc. Nat1. Acad. Sci. 97: 1512-1515.

Satoh, S., Hijikata, M., Handa, H., and Shimotohno, K. 1999. 
Caspase-mediated cleavage of eukaryotic translation initiation factor subunit $2 \alpha$. Biochem. J. 342: 65-70.

Scheetz, A.J., Nairn, A.C., and Constantine-Paton, M. 2000. NMDA receptor-mediated control of protein synthesis at developing synapses. Nat. Neurosci. 3: 211-216.

Seggerson, K. and Moore, P.B. 1998. Structure and stability of variants of the sarcin-ricin loop of 28S rRNA: NMR studies of the prokaryotic SRL and a functional mutant. RNA 4: 1203-1215.

Sella, O., Gerlitz, G., Le, S.Y., and Elroy-Stein, O. 1999. Differentiation-induced internal translation of c-sis mRNA: Analysis of the cis elements and their differentiation-linked binding to the hnRNP C protein. Mol. Cell. Biol. 19: 54295440.

Shine, J. and Dalgarno, L. 1975. Determinant of cistron specificity in bacterial ribosomes. Nature 254: 34-38.

Shiroki, K., Isoyama, T., Kuge, S., Ishii, T., Ohmi, S., Hata, S., Suzuki, K., Takasaki, Y., and Nomoto, A. 1999. Intracellular redistribution of truncated La protein produced by poliovirus 3Cpro-mediated cleavage. J. Virol. 73: 2193-2200.

Sizova, D.V., Kolupaeva, V.G., Pestova, T.V., Shatsky, I.N., and Hellen, C.U. 1998. Specific interaction of eukaryotic translation initiation factor 3 with the $5^{\prime}$ nontranslated regions of hepatitis $\mathrm{C}$ virus and classical swine fever virus RNAs. J. Virol. 72: 4775-4782.

Smith, D.B., Mellor, J., Jarvis, L.M., Davidson, F., Kolberg, J., Urdea, M., Yap, P.L., and Simmonds, P. 1995. Variation of the hepatitis $\mathrm{C}$ virus 5 ' non-coding region: Implications for secondary structure, virus detection and typing. The International HCV Collaborative Study Group. J. Gen. Virol. 76: $1749-1761$.

Spahn, C.M.T., Kieft, J.S., Grassucci, R.A., Penczek, P., Zhou, K., Doudna, J.A., and Frank, J. 2001. Hepatitis C virus RNA induced changes in the conformation of the $40 \mathrm{~S}$ subunit. Science 291: 1959-1962.

Stein, I., Itin, A., Einat, P., Skaliter, R., Grossman, Z., and Keshet, E. 1998. Translation of vascular endothelial growth factor mRNA by internal ribosome entry: Implications for translation under hypoxia. Mol. Cell. Biol. 18: 3112-3119.

Stewart, S.R. and Semler, B.L. 1998. RNA structure adjacent to the attenuation determinant in the $5^{\prime}$-non-coding region influences poliovirus viability. Nucleic Acids Res. 26: 53185326.

Stoneley, M., Paulin, F.E., Le Quesne, J.P., Chappell, S.A., and Willis, A.E. 1998. C-Myc 5' untranslated region contains an internal ribosome entry segment. Oncogene 16: 423-428.

Stoneley, M., Chappell, S.A., Jopling, C.L., Dickens, M., MacFarlane, M., and Willis, A.E. 2000a. c-Myc protein synthesis is initiated from the internal ribosome entry segment during apoptosis. Mol. Cell. Biol. 20: 1162-1169.

Stoneley, M., Subkhankulova, T., Le Quesne, J.P., Coldwell, M.J., Jopling, C.L., Belsham, G.J., and Willis, A.E. 2000b. Analysis of the c-myc IRES; a potential role for cell-type specific trans-acting factors and the nuclear compartment. Nucleic Acids Res. 28: 687-694.

Svitkin, Y.V., Maslova, S.V., and Agol, V.I. 1985. The genomes of attenuated and virulent poliovirus strains differ in their in vitro translation efficiencies. Virology 147: 243-252.

Tranque, P., Hu, M.C., Edelman, G.M., and Mauro, V.P. 1998. rRNA complementarity within mRNAs: A possible basis for mRNA-ribosome interactions and translational control. Proc. Natl. Acad. Sci. 95: 12238-12243.

Trono, D., Andino, R., and Baltimore, D. 1988. An RNA sequence of hundreds of nucleotides at the $5^{\prime}$ end of poliovirus RNA is involved in allowing viral protein synthesis. J. Virol. 62: 2291-2299.
Tsukiyama-Kohara, K., Iizuka, N., Kohara, M., and Nomoto, A. 1992. Internal ribosome entry site within hepatitis $\mathrm{C}$ virus RNA. J. Virol. 66: 1476-1483.

Vagner, S., Gensac, M.C., Maret, A., F. Bayard, F. Amalric, H. Prats, and A.C. Prats. 1995a. Alternative translation of human fibroblast growth factor 2 mRNA occurs by internal entry of ribosomes. Mol. Cell. Biol. 15: 35-44.

Vagner, S., Waysbort, A., Marenda, M., Gensac, M.C., Amalric, F., and Prats, A.C. 1995b. Alternative translation initiation of the Moloney murine leukemia virus mRNA controlled by internal ribosome entry involving the p57/PTB splicing factor. J. Biol. Chem. 270: 20376-20383.

Walter, B.L., Nguyen, J.H., Ehrenfeld, E., and Semler, B.L. 1999. Differential utilization of poly $(\mathrm{rC})$ binding protein 2 in translation directed by picornavirus IRES elements. RNA 5: 1570-1585.

Wang, C., Sarnow, P., and Siddiqui, A. 1993. Translation of human hepatitis $\mathrm{C}$ virus RNA in cultured cells is mediated by an internal ribosome-binding mechanism. J. Virol. 67: 33383344.

Whetter, L.E., Day, S.P., Elroy-Stein, O., Brown, E.A., and Lemon, S.M. 1994. Low efficiency of the $5^{\prime}$ nontranslated region of hepatitis A virus RNA in directing cap-independent translation in permissive monkey kidney cells. I. Virol. 68: 5253-5263.

Wilson, J.E., Pestova, T.V., Hellen, C.U., and Sarnow, P. 2000a. Initiation of protein synthesis from the A site of the ribosome. Cell 102: 511-520.

Wilson, J.E., Powell, M.J., Hoover, S.E., and Sarnow, P. 2000b. Naturally occurring dicistronic cricket paralysis virus RNA is regulated by two internal ribosome entry sites. Mol. Cell. Biol. 20: 4990-4999.

Yamanaka, S., Poksay, K.S., Arnold, K.S., and Innerarity, T.L. 1997. A novel translational repressor mRNA is edited extensively in livers containing tumors caused by the transgene expression of the apoB mRNA- editing enzyme. Genes \& Dev. 11: 321-333.

Yang, Q. and Sarnow, P. 1997. Location of the internal ribosome entry site in the $5^{\prime}$ non-coding region of the immunoglobulin heavy-chain binding protein $(\mathrm{BiP})$ mRNA: Evidence for specific RNA-protein interactions. Nucleic Acids Res. 25: 2800-2807.

Ye, X., Fong, P., Iizuka, N., Choate, D., and Cavener, D.R. 1997. Ultrabithorax and Antennapedia 5' untranslated regions promote developmentally regulated internal translation initiation. Mol. Cell. Biol. 17: 1714-1721.

Yueh, A. and Schneider, R.J. 1996. Selective translation initiation by ribosome jumping in adenovirus-infected and heatshocked cells. Genes \& Dev. 10: 1557-1567.

- 2000. Translation by ribosome shunting on adenovirus and hsp70 mRNAs facilitated by complementarity to $18 \mathrm{~S}$ rRNA. Genes \& Dev. 14: 414-421. 


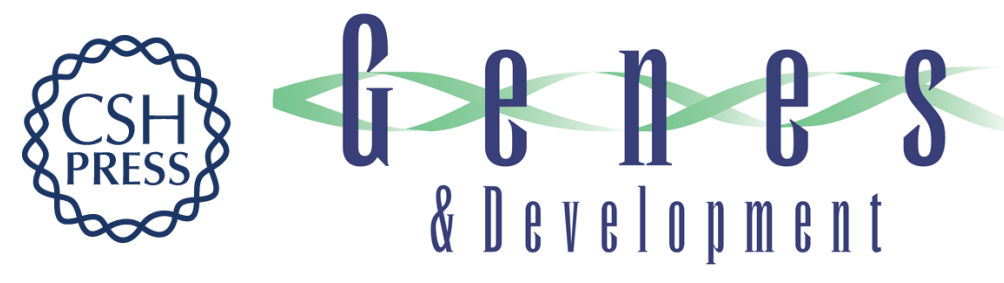

\section{Internal ribosome entry sites in eukaryotic mRNA molecules}

Christopher U.T. Hellen and Peter Sarnow

Genes Dev. 2001, 15:

Access the most recent version at doi:10.1101/gad.891101

References This article cites 177 articles, 108 of which can be accessed free at: http://genesdev.cshlp.org/content/15/13/1593.full.html\#ref-list-1

License

Email Alerting Receive free email alerts when new articles cite this article - sign up in the box at the top Service right corner of the article or click here.

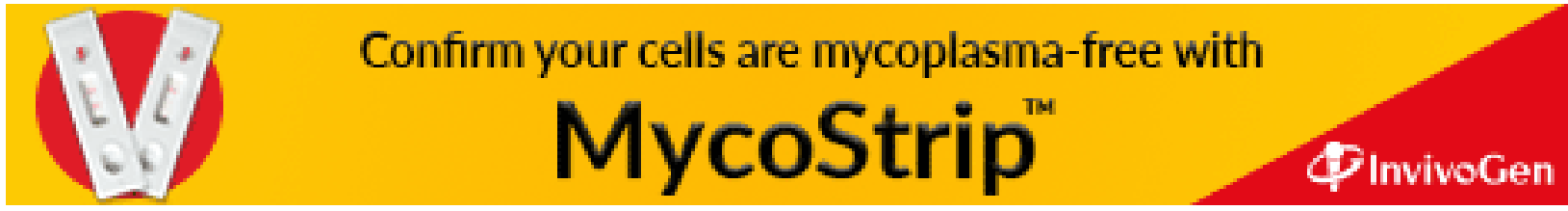

